\title{
The prognostic outcome of 'type 2 diabetes mellitus and breast cancer' association pivots on hypoxia-hyperglycemia axis
}

\author{
Ilhaam Ayaz Durrani, Attya Bhatti ${ }^{*}$ (D) and Peter John
}

\begin{abstract}
Type 2 diabetes mellitus and breast cancer are complex, chronic, heterogeneous, and multi-factorial diseases; with common risk factors including but not limited to diet, obesity, and age. They also share mutually inclusive phenotypic features such as the metabolic deregulations resulting from hyperglycemia, hypoxic conditions and hormonal imbalances. Although, the association between diabetes and cancer has long been speculated; however, the exact molecular nature of this link remains to be fully elucidated. Both the diseases are leading causes of death worldwide and a causal relationship between the two if not addressed, may translate into a major global health concern. Previous studies have hypothesized hyperglycemia, hyperinsulinemia, hormonal imbalances and chronic inflammation, as some of the possible grounds for explaining how diabetes may lead to cancer initiation, yet further research still needs to be done to validate these proposed mechanisms. At the crux of this dilemma, hyperglycemia and hypoxia are two intimately related states involving an intricate level of crosstalk and hypoxia inducible factor 1 , at the center of this, plays a key role in mediating an aggressive disease state, particularly in solid tumors such as breast cancer. Subsequently, elucidating the role of HIF1 in establishing the diabetes-breast cancer link on hypoxia-hyperglycemia axis may not only provide an insight into the molecular mechanisms underlying the association but also, illuminate on the prognostic outcome of the therapeutic targeting of HIF1 signaling in diabetic patients with breast cancer or vice versa. Hence, this review highlights the critical role of HIF1 signaling in patients with both T2DM and breast cancer, potentiates its significance as a prognostic marker in comorbid patients, and further discusses the potential prognostic outcome of targeting HIF1, subsequently establishing the pressing need for HIF1 molecular profiling-based patient selection leading to more effective therapeutic strategies emerging from personalized medicine.
\end{abstract}

Keywords: Breast cancer, Type 2 diabetes mellitus, T2DM, Hypoxia inducible factor 1, HIF1, Hypoxia, Hyperglycemia

\section{Introduction}

Diabetes and cancer are two complex yet increasingly prevalent, chronic, metabolic morbidities [1], emerging globally as major public health concerns [2]. Diabetes with a global occurrence of 422 million in 2014 [3], is the seventh leading cause of death worldwide [4], while cancer is undisputedly the second most leading

*Correspondence: attyabhatti@asab.nust.edu.pk

Atta-ur-Rehman School of Applied Biosciences (ASAB), National University of Sciences and Technology (NUST), H-12, Islamabad, Pakistan cause of death with 17 million cases in 2018 alone and an expected 27.5 million new cases by 2040 [5], its prevalence is set on ever increasing.

Diabetes itself is a group of various metabolic disorders, characterized by hyperglycemia resulting from insulin deficiency, its inaction or both, with a spectrum of other complications affecting major body organs associated with it. It can be classified into type 1 and type 2 diabetes mellitus and gestational diabetes [6]. Type 1 diabetes mellitus (T1DM) is insulin dependent and caused by the inability of the pancreatic beta cells 
to synthesize insulin, accounted for by the autoimmune destruction of beta cells [7]. Type 2 diabetes mellitus (T2DM), on the other hand is not insulin dependent; rather it is characterized by insulin resistance due to the inability of cells to respond to insulin followed by compensatory hyperinsulinemia [8]. Cancer too is a heterogeneous disease and can be classified into many distinct types based on its site of origin and other clinic-pathological features and molecular signatures $[9,10]$.

There have been many speculations since the twentieth century, linking diabetes to cancer and increasing evidence has associated diabetes, particularly type 2 diabetes mellitus (T2DM) with cancer risk, prognosis and treatment. These are supported by numerous epidemiological studies that revealed a positive correlation of T2DM with many types of cancer, such as pancreas [11], liver [12], endometrium [13], colon-rectum [14], bladder [15], and breast cancer [16].

However, it is noteworthy that not all cancers associate positively with diabetes. Prostate, kidney and ovarian cancers are inversely associated with diabetes i.e. diabetic patients are at a decreased risk of developing these cancers [17], and lung cancer has reportedly shown no association with either type of diabetes.

Cancers of liver, endometrium and pancreas have shown doubled risk as compared to breast, colon, rectal and bladder cancers in T2DM patients. Furthermore, cancers that associate with one type of diabetes may not necessarily also associate with the other type, such as breast cancer which only associates with T2D and not with T1D [18]. Insulin and other drugs have also been associated with the diabetes-cancer risk; however, the debate is still ongoing [19-24]. Hence, with review emerges complexities in the link between diabetes and cancer and the multi-faceted relationship these two diseases hold. The increase in cancer risk in diabetic patients may be slight to moderate, yet given the status of diabetes as a global epidemic, the socioeconomic impact of this positive association may be significantly burdening [25].

Following the discovery of the hallmarks of cancer [26, 27], the metabolic nature of some of the deregulations involved in cancer has become a focus of study worldwide and these may be in line with the metabolic abnormalities' characteristic of diabetes. Yet, the root cause of this diabetes- cancer association is still under explored and hence not fully clear. There have been multiple possible molecular mechanisms proposed to explain the causal relationship [28]. The more extensively researched and hence the better understood hypotheses include hyperinsulinemia and hyperglycemia [29]. These along with inflammation and oxidative stress related conditions may be of prime importance in explaining the link and hence these interconnected states would be reviewed further in this article.

The etiology underlying these two diseases and the interplay of common pathways may help to explain the molecular basis of the positive correlation. Diabetes involves metabolic alterations, hormonal imbalances particularly of insulin/insulin growth factor-1 and adiponectin/ leptin, and immune response such as elevated levels of pro-inflammatory cytokines like tumor necrosis factor-a (TNF- $\alpha$ ), and all these features it shares with cancer. These commonalities may give insight into the cross talk that initiates carcinogenesis in diabetic patients and may reflect on a cumulative effect of the converging and diverging pathways in combination with the differential pathways modulating the two-way relationship between diabetes mellitus and cancer; of diabetes as a cause and as an aftermath of cancer. Additionally, both these diseases share certain risk factors including diet, exercise, ageing and obesity [30], hence these and the reported crosstalk within the insulin and cancer signaling pathways not only spark an interest in elucidating the correlation between diabetes and cancer but it may also be employed to understand the connection.

Hyperinsulinemia may be a direct causal factor for carcinogenesis. Findings from numerous studies have consistently linked hyperinsulinemia, which is characteristic of type 2 diabetes mellitus with increased incidence of cancer [31,32]. Insulin has mitogenic properties and may lead to cancer initiation itself and via increasing Insulinlike growth factor (IGF-1), which has both mitogenic and anti-apoptotic properties.

Furthermore, hyperglycemia is a hallmark of diabetes [33], and is also a risk factor for cancer progression [34]. It has shown to trigger the HIF1 pathway via upregulation of HIF1- $\alpha$ gene expression, eventually leading to an anti-apoptotic cell response and activation of oncolytic pathways in specific cell types [35-37]. A study conducted on rat pancreatic beta cells reported high glucose induced increased oxygen consumption, leading to hypoxia and subsequent HIF1 activation, and associated it with a slower decrease in beta cell function [38]. In another instance, hyperglycemia mediated HIF1 activation was also correlated with glucose intolerance [39]. However, there are studies showing that hyperglycemia in diabetic patients impair the HIF pathway [35], differing with studies which show an increased expression of HIF1- $\alpha$ under hyperglycemia [40]. Hence, the critical role of HIF1 in establishing the diabetes-cancer link needs to be fully elucidated by probing into the intricate crosstalk between HIF1 and insulin signaling.

Other proposed potential biological mechanisms include hormonal imbalances disrupting the estrogenprogesterone and adiponectin/lectin axes and also 
obesity as an independent risk factor [41-44]. Still, the current knowledge pertaining to the exact nature of the molecular mechanisms linking diabetes with cancer and what is currently known only gives a very complex picture of status quo. Latent cancer may also contribute to the development of diabetes and hence lead to reverse causality [45]. Either way, co-occurrence of diabetes and cancer seems to worsen the prognosis and increase mortality $[46,47]$.

This review however focuses on T2DM- breast cancer association by discussing disease epidemiology, pathogenesis and underlying potential molecular mechanisms establishing a crosstalk between diabetes and breast cancer signaling pathways and highlights on the relevance of hypoxia-hyperglycemia axis established, in explaining this molecular association. It presents an overview of series of events that may initiate carcinogenesis in mammary tissue and contribute to its progression in diabetic patients, outlining the plausible molecular routes from diabetic state to breast carcinogenesis, with a particular emphasis on the role of HIF1 in mediating this transition in diseased state. It further discusses the outcome of this association on breast cancer subtype specificity, and relates this dynamic molecular crosstalk to explain the development of hallmarks of cancer, Additionally, this review establishes on the multi-faceted, bidirectional and dual relationship between diabetes, its treatment and breast cancer subtype specific incidence, prognosis and therapy.

Breast cancer was specifically selected as an area of focus, as it shares several characteristics with T2DM, including its characterization by regions of hypoxia, its composition of adipose tissue, a major site affected by T2DM, and the high incidence of breast cancer, in Pakistan, and worldwide.

Understanding the diabetes- breast cancer link on hyperglycemia-hypoxia axis may give way to understanding the role of HIF1 in developing this link, which could then be employed to determine the prognostic outcome of targeting HIF1 in comorbid patients. This review may also inspire further research and identification of potential biomarkers for early detection of breast cancer in diabetic patients and prognosis prediction in comorbid patients.

\section{Literature review article selection}

For this literature review, the online database PubMed was searched through using the keywords "diabetes" (OR "T2DM" OR type 2 diabetes mellitus) AND "breast cancer" (OR "breast carcinoma") AND "hypoxia inducible factor 1" (OR "HIF1") in all possible combinations. A total of 19 articles were extracted for the period 20082021, of which only 9 matched the relevancy of all three keyword categories inclusion criteria. Of these 1 article was in Chinese, hence could not be fully reviewed here. Out of the remaining, 6 discuss the role of potential therapeutics targeting diabetes and breast cancer, while also implicating HIF1- $\alpha$. Additionally, 3 articles were extracted from other searches such as studying review articles to extract references for original articles relevant to the research topic as outlined in Fig. 1 enlisting the article selection process. For this review, 11 articles were eligible for inclusion and are discussed henceforth.

\section{Epidemiological links of diabetes with breast cancer}

Breast cancer is the fifth most common cause of death [48], and the most commonly diagnosed cancer in women [49]. There were over 2 million cases reported in 2018 alone. Pakistan has the highest breast cancer incidence rate in Asia, with approximately 90,000 cases reported every year and 40,000 deaths. It is reported that one in every nine Pakistani women is likely to develop breast cancer at some stage in her life [50].

Numerous studies have linked diabetes with a small yet increased breast cancer risk and even worse prognosis as summarized in Table 1. So far, this has been attributed to insulin resistance and associated corresponding hyperinsulinemia. For instance, studies tracking death in breast cancer patients reported an increasing trend for women with diabetes, and also supported a stronger independent link with prognosis as compared to breast cancer risk [51], which can be explained by higher insulin levels, late diagnosis, less aggressive treatment plan or diabetes associated complications or co-morbidity [52, 53].

Another follow up study of 116,488 female nurses revealed 6220 women with T2DM, and 5189 incident cases of invasive mammary carcinoma in the course of time. A modestly elevated risk for breast cancer incidence in T2DM patients was reported, independent of the influence of other risk factors including age, obesity and family history, physical activity and reproductive factors [54].

T2DM as a prognostic factor in breast cancer patients has also been associated with decreased overall survival. A cohort study of one million U.S adults revealed a $16 \%$ increase in breast cancer mortality in patients with preexisting diabetes [60]. This was consistent with multiple other studies reporting a higher all-cause mortality in diabetic women [61]. Hence co-occurrence of diabetes with breast cancer may worsen the prognosis and overall survival by increasing the risk of wound infection and hence subjection to a delay in administration of adjuvant chemotherapy. This may contribute to worsening of the patient's state [62]. Diabetic treatment may also interfere with disease outcome and patient survival. Studies have 


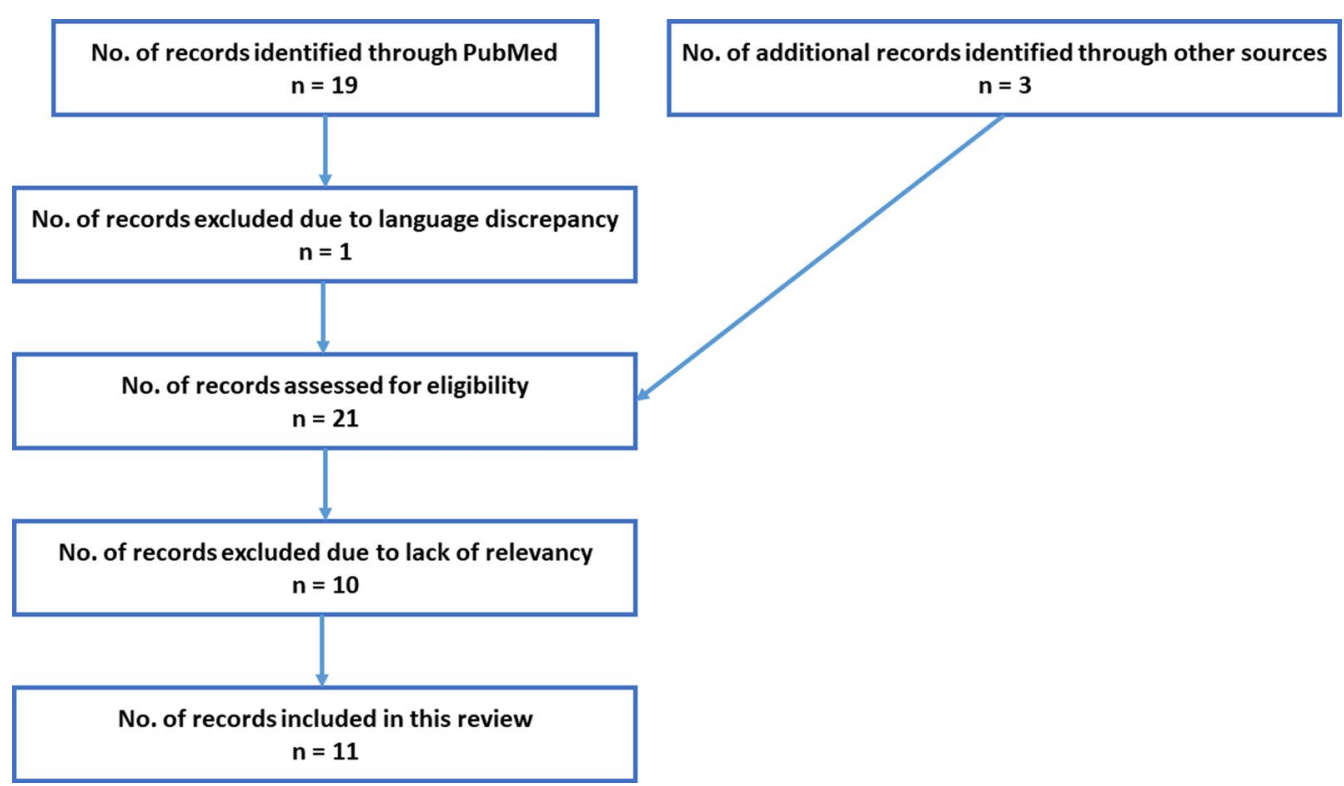

Fig. 1 Article selection process outline. Out of 21 articles matching the keywords search results, only 11 matched the inclusion criteria and hence were included in this review

linked it to distant metastases and increased recurrence rates in breast cancer [63].

Hence, another layer of complexity arises as anti-diabetic treatments have also shown to impact breast cancer risk and prognosis. Insulin sensitizers such as metformin decreases insulin resistance by altering the PI3K/AKT/ mTOR pathway [64]. This may potentially contribute to the anti-cancer effects of metformin such as a decrease in cell proliferation and induction of apoptosis when tested on cancer cell lines [65]. A recent population based case-case study in 2019, evaluated the association between T2DM, its medications and breast cancer risk, particularly in different molecular subtypes [66]. The study involved 4557 breast cancer patients, and showed that women with T2DM had a $38 \%$ increased risk of triple negative breast cancer, as compared to women lacking T2DM history, and particularly for those prescribed with metformin for long-term usage. On the other hand, in the Women's Health Initiative study, metformin use was found to correspond with a lower risk of hormone receptor positive and HER2 negative breast cancer [67]. Contrary to this, epidemiological analysis based on the Black Women's Health Study cohort, reported no significant differences for breast cancer risk based on ER status, diabetic condition and diabetic treatment [68]. The inconsistency in these findings may be explained by a potential misclassification bias originating from selfreported data on metformin use, and even by the overall prevalence of diabetic medication amongst the study population. Moreover, metformin's role as an adjuvant in chemotherapy for breast cancer has also been reviewed [69].

Other diabetic treatments include externally administrated insulin, which is known for its mitogenic effects [70], and has been associated with a non-significant increased risk of breast cancer [71]. While, insulin glargine is associated with $30 \%$ increased risk [72], and metaanalyses investigating breast cancer risk associated with sulfonylurea use have also yielded mixed results, lacking consistency [73-75], and hence further research is needed to substantiate the association between diabetic treatments and breast cancer risk.

Cancer treatment may also contribute to the development of diabetes, however breast cancer in patients with pre-existing diabetes has shown increased disease severity [76]. The type of breast cancer treatment is also known to influence the incidence of T2DM in breast cancer patients [77]. In case of patients subjected to chemotherapy/surgery, $17.2 \%$ reported the development of T2DM [78]. Patients who underwent adjuvant chemotherapy, hormone therapy, aromatase/PI3K inhibitors and morphine users showed an increased risk of developing T2DM [79-82]. Additionally, post-menopausal breast cancer is also shown to associate with higher T2DM incidence. Hence, the co-existence of diabetes with breast cancer may influence breast cancer prognosis and its treatment strategy as well.

Apart from insulin itself, several other nodes from insulin signaling have been implicated in breast cancer. (IGF) IGF binding proteins (-BP) regulate the 
Table 1 Epidemiological data linking diabetes with breast cancer

\begin{tabular}{|c|c|c|c|c|c|c|c|c|}
\hline Sr. No. & Study name & Country & Study type & $\begin{array}{l}\text { Population/ } \\
\text { Sample size }\end{array}$ & Study period & Age group & $\begin{array}{l}\text { Characteristic } \\
\text { findings }\end{array}$ & Refs \\
\hline 1 & $\begin{array}{l}\text { Nurse Health } \\
\text { Study }\end{array}$ & USA & Follow up & 116,488 Nurses & 1976-1988 & $30-55$ & $\begin{array}{l}\text { Women with } \\
\text { T2DM had } \\
\text { a modestly } \\
\text { elevated breast } \\
\text { cancer inci- } \\
\text { dence }\end{array}$ & {$[54]$} \\
\hline 2 & $\begin{array}{l}\text { Long Island } \\
\text { Breast Cancer } \\
\text { Study Project }\end{array}$ & USA & $\begin{array}{l}\text { Population based } \\
\text { study using data } \\
\text { from case-con- } \\
\text { trol \& Follow up } \\
\text { studies }\end{array}$ & 1508 & 1996-1997 & $30+$ & $\begin{array}{l}\text { Diabetes associ- } \\
\text { ated increased } \\
\text { breast cancer } \\
\text { incidence in } \\
\text { older and non- } \\
\text { white women } \\
\text { due to all } \\
\text { reasons }\end{array}$ & {$[55]$} \\
\hline 3 & $\begin{array}{l}\text { SEER-Medicare } \\
\text { based study }\end{array}$ & & $\begin{array}{l}\text { Observational } \\
\text { Cohort }\end{array}$ & 2418 & $2001-2007$ & $\begin{array}{l}>80 \\
\text { Mean age: } 77.8\end{array}$ & $\begin{array}{l}\text { Diabetes associ- } \\
\text { ated with } \\
\text { advanced } \\
\text { cancer stage } \\
\text { and increased } \\
\text { mortality }\end{array}$ & {$[56]$} \\
\hline 4 & $\begin{array}{l}\text { Meta-analysis of } \\
\text { diabetes mellitus } \\
\text { and risk of breast } \\
\text { cancer }\end{array}$ & $\begin{array}{l}\text { Various (From } \\
\text { North } \\
\text { America, } \\
\text { Europe \& } \\
\text { Asia) }\end{array}$ & $\begin{array}{l}\text { Meta-analysis of } \\
\text { case-control } \\
\text { \&cohort studies }\end{array}$ & $\begin{array}{l}20 \text { Studies }(30,568 \\
\text { cases) }\end{array}$ & $1966-2007$ & $20-95$ & $\begin{array}{l}20 \% \text { increased } \\
\text { breast cancer } \\
\text { risk in women } \\
\text { with diabetes }\end{array}$ & [17] \\
\hline 5 & $\begin{array}{l}\text { Retrospective } \\
\text { cohort study in } \\
\text { China }\end{array}$ & China & $\begin{array}{l}\text { Retrospective } \\
\text { Cohort }\end{array}$ & 36 cases & $2002-2008$ & - & $\begin{array}{l}\text { Increased risk } \\
\text { of developing } \\
\text { breast cancer in } \\
\text { T2DM patients }\end{array}$ & {$[57]$} \\
\hline 6 & $\begin{array}{l}\text { Diabetes increases } \\
\text { risk of breast } \\
\text { cancer }\end{array}$ & Various & $\begin{array}{l}\text { Meta-analysis of } \\
\text { case-control \& } \\
\text { cohort studies }\end{array}$ & $\begin{array}{l}43 \text { studies } \\
\quad(422,631 \text { cases })\end{array}$ & $\begin{array}{l}\text { Oldest Study from } \\
1990 \\
\text { Latest from } 2012\end{array}$ & Varied & $\begin{array}{l}\text { T2DM increases } \\
\text { the risk of } \\
\text { breast cancer in } \\
\text { women }\end{array}$ & {$[58]$} \\
\hline 7 & $\begin{array}{l}\text { Random effects } \\
\text { model based } \\
\text { meta-analysis }\end{array}$ & $\begin{array}{l}\text { Various (From } \\
\text { North } \\
\text { America, } \\
\text { Europe \& } \\
\text { Asia) }\end{array}$ & Meta-analysis & $\begin{array}{l}39 \text { independent } \\
\text { observational } \\
\text { studies (58,690 } \\
\text { cases) }\end{array}$ & $\begin{array}{l}\text { Oldest Study from } \\
1993 \\
\text { Latest from } 2011\end{array}$ & All ages & $\begin{array}{l}\text { 27\% Increased risk } \\
\text { for breast cancer } \\
\text { in women with } \\
\text { T2DM (reduced } \\
\text { to } 16 \% \text { after } \\
\text { adjustment for } \\
\text { BMI) }\end{array}$ & [18] \\
\hline 8 & $\begin{array}{l}\text { T2DM as a risk } \\
\text { factor for female } \\
\text { breast cancer }\end{array}$ & Pakistan & $\begin{array}{l}\text { Case-control } \\
\text { study }\end{array}$ & 400 patients & 2014-15 & & $\begin{array}{l}17.69 \% \text { breast } \\
\text { cancer patients } \\
\text { reported dia- } \\
\text { betes }\end{array}$ & [59] \\
\hline
\end{tabular}

Data represented here has been retrieved from 7 published works including 3 meta-analyses and other population based studies

bioavailability of IGF1 and IGF2, with IGFBP2 and IGFBP3 most abundantly circulating in blood [83]. Meta-analyses reveal that IGFBP2 and IGFBP3 both correlate positively with breast cancer and poor prognosis in patients [83, 84]. Hence, the multi-layered relationship between T2DM and breast cancer needs further probing into to fully comprehend the complexities of this bi-directional association.

\section{Prevalence, risk factors and mutual features of diabetes and breast cancer Etiology of diabetes}

Diabetes is a complex metabolic syndrome that includes metabolic and hormonal disorders such as type 1 diabetes mellitus (T1DM), type 2 diabetes mellitus (T2DM) and gestational diabetes. A prolonged existence of hyperglycemic conditions in diabetic patients is associated with organ damage, failure and dysfunction, particularly of kidneys, heart, eyes, nerves and blood vessels [85]. 
The vast majority of diabetes cases fall into type 1 and 2 diabetes mellitus, where the latter being significantly more prevalent. T1DM is caused by an absolute lack of insulin secretion due to the autoimmune mediated destruction of beta cells in pancreas, which secrete insulin. This form of diabetes contributes to $5-10 \%$ of the total reported cases. T2DM, on the other hand is attributed to a combination of insulin resistance and a lack of / inadequacy of insulin secretory response. T2DM accounts for $\sim 90-95 \%$ of the reported cases of diabetes [86]. The risk of developing T2DM is associated with factors such as age, obesity, and lack of physical activity. The genetics of this type of diabetes is complex and still not clear.

Type 2 diabetes originates in various sites including adipose tissue which becomes insulin resistant caused by alterations in the insulin signaling pathway [87], and so it is important to understand the pathway that directly impacts diabetes.

\section{Etiology of breast cancer}

Breast cancer originates in breast tissue which is composed mainly adipose and fibroglandular tissue, supporting lobules containing milk producing glands and ducts linking glands to the nipple [88, 89]. It is a complex, heterogeneous disease and presents a diverse risk profile. Even though all the causes of breast cancer are not fully understood, some of the risk factors include genetic mutations deregulating crucial signaling pathways and activation of oncogenes, increased body weight and obesity, prolonged exposure to carcinogens and alterations in the immune conditions which may promote cancer growth [90]. Breast cancer can be further classified into different groups based on their hormone receptor profiles and other categories as summarized in Fig. 2.

\section{Adipose tissue: common ground for T2DM and breast cancer}

Adipose tissue is one the major sites affected by the development of T2DM. Deregulation in the insulin-AKT pathway leads to the development of the insulin resistance in adipocytes. Interestingly, it also forms a major and crucial component of breast tumor microenvironment, and is involved in major energy storage and glucose expenditure of the body $[89,100]$. It also serves as an endocrine organ, secreting adipokines such as leptin and adiponectin, cytokines like interleukins and TNF$\alpha$, chemokine CXCL- 8 amongst others, growth factors including but not limited to vascular endothelial growth factor (VEGF) and IGF, and other factors such as aromatase, all of which are associated with breast cancer [98-100].

\section{Metabolic reprogramming}

Molecular alterations pertaining to diabetic phenotype such as defects in insulin signaling leading to lack of response to insulin and subsequent hyperinsulinemia, may ultimately promote tumorigenesis via HIF1 regulation, increased glucose uptake and its utilization, making energy more readily available to afford the

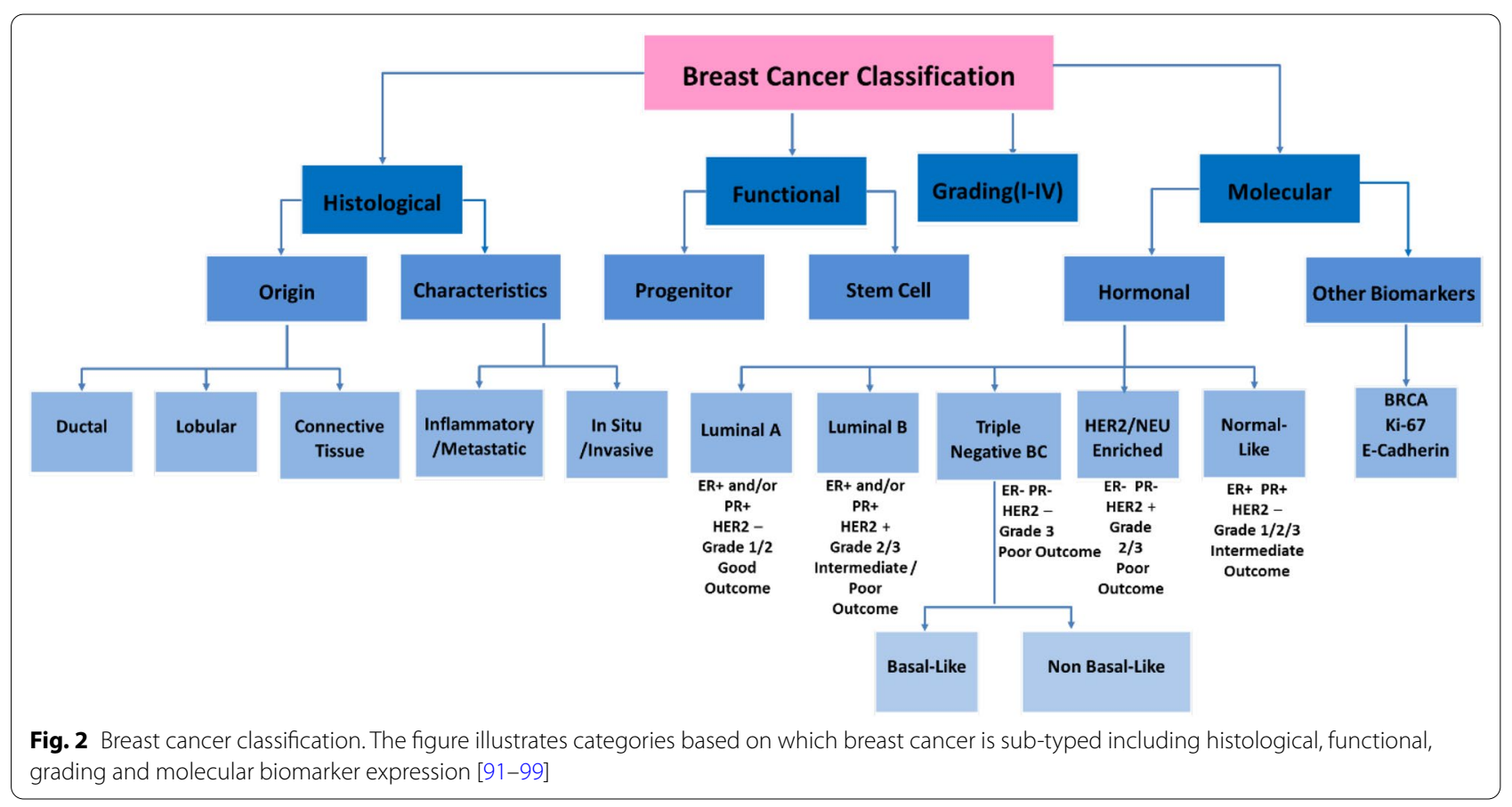


uncontrolled growth of tumor [101]. Once HIF1 is activated, it increases the transcriptional expression of metabolic enzymes such as lactate dehydrogenase (LDH), and pyruvate dehydrogenase kinase (PDK1) which blocks the conversion of pyruvate to acetyl-coA, hence preventing pyruvate molecules from entering the TCA cycle.

\section{Signaling cascades and their crosstalk in diabetes and breast cancer Insulin signaling}

Insulin is a peptide hormone released in response to high blood glucose level by pancreatic beta cells and it stimulates increased uptake of glucose by cell, glycogen synthesis in liver, gluconeogenesis, protein catabolism and fatty acid esterification on binding its receptor and initiating downstream signaling. It also inhibits lipolysis, autophagocytosis, proteosomal activity and apoptosis. Elevated insulin levels are associated with mitogenic effects in synergy with increased bioavailable IGF-1 levels.

Insulin/IGF1 signaling pathway controls metabolism and growth. Both insulin and IGF1, two key players required to trigger this pathway act on two closely related tyrosine kinases which when phosphorylated initiates a series of further phosphorylation events that regulate metabolic and cell growth pathways. Alterations in this network can lead to insulin resistance and diabetes [102].

Insulin and IGF-1 bind to and lead to a conformational change in insulin and IGF-1 receptors, respectively, following auto-phosphorylation. This leads to the recruitment and phosphorylation of receptor substrates such as insulin receptor substrate (IRS) and Shc proteins. IRS then recruits PI3K, and hence activates the AKT-PI3K pathway, which controls cell survival and growth. AKT also regulates insulin-mediated response including glucose transport, gluconeogenesis, glycogen synthesis and lipid synthesis. Shc activates the MAPK pathway, which then mediates cellular proliferation and transcription.

Hence, insulin and its signaling pathway play a crucial role in energy homeostasis by regulating glucose and lipid metabolism and by acting directly on liver, skeletal muscle and adipose tissue predominantly. Lack of insulin or its inadequacy in cases of diabetes leads to alterations in the pathway, which greatly influence the disease prognosis.

\section{HIF1 signaling}

Tumor hypoxia is a driving force for metabolic alterations in cancer. Hypoxic conditions especially in solid tumors such as breast cancer trigger HIF1 signaling, which plays a central role in mediating cell's adaptive response to hypoxia.
HIF1 is a transcription factor belonging to the HIF family, regulated by both hypoxic and non-hypoxic conditions. It is a hetero-dimer with the two subunits constitutively produced [103]. However, under normoxic conditions, HIF1- $\alpha$ is proteosomally degraded after being hydroxylated by oxygen sensing PHD and FIH-1 enzymes. If the oxygen levels fall, the HIF1- $\alpha$ subunit is not hydroxylated, hence leading to its stabilization and binding to HIF1- $\beta$ subunit to activate the downstream HIF1 signaling pathway [104].

Hypoxia independent activation of HIF1 pathway under normoxia has been shown to be triggered by signaling molecules such as nitric oxide, interleukin 1 (IL-1), tumor necrosis factor alpha (TNF- $\alpha$ ), angiotensin II and growth factors such as epidermal growth factors, insulin and insulin like growth factor and also mediated by PI3K-AKT pathway $[105,106]$.

P53 regulates HIF1- $\alpha$ stability whereas the ERK/ MAPK pathway regulates both HIF1- $\alpha$ stability and its activation; ERK is involved in the transcriptional activation and synthesis of HIF1- $\alpha$ [107]. PI3K-AKT pathway also regulates HIF1 protein translation via the action of mTOR on other genes controlling HIF1- $\alpha$ protein translation. Additionally, IL- $1 \beta$ also leads to HIF1 signaling in case of an inflammation. HIF1 in return, increases the entry of glucose into the cells, the glycolytic flux and the conversion of pyruvate into lactate [108].

Additionally, the hypoxia-independent regulation of HIF1 is mediated by signaling such as the insulinPI3K-AKT, MAPK/ERK, IL-1 and NF-KB pathways. Once HIF1 $\alpha-\beta$ complex forms, it transcriptionally activates various target genes including glucose transporter GLUT1 and glycogen synthase kinase (GSK) which regulate metabolism, and e- cadherin and matrix metalloproteinase (MMP) proteins leading to epithelial to mesenchymal transition and metastasis. It also regulates autophagy and cell death via BCL2/adenovirus E1B $19 \mathrm{kDa}$ protein-interacting protein (BNIP3) and p53, and angiogenesis by upregulating VEGF and MMPs as represented by Fig. 3.

\section{PI3K/AKT and ERK/MAPK pathways}

AKT-PI3K pathway crucial for cell survival [117], and the ERK/MAPK pathway with its role in cell proliferation, converge at HIF1 signaling [118, 119], after diverging from insulin pathway $[120,121]$. Both these pathways are central to cancer signaling and have been thoroughly reviewed elsewhere [122, 123], however it is important to relate to all these signaling cascades together to completely envision the complex picture within a developing cancerous cell. 


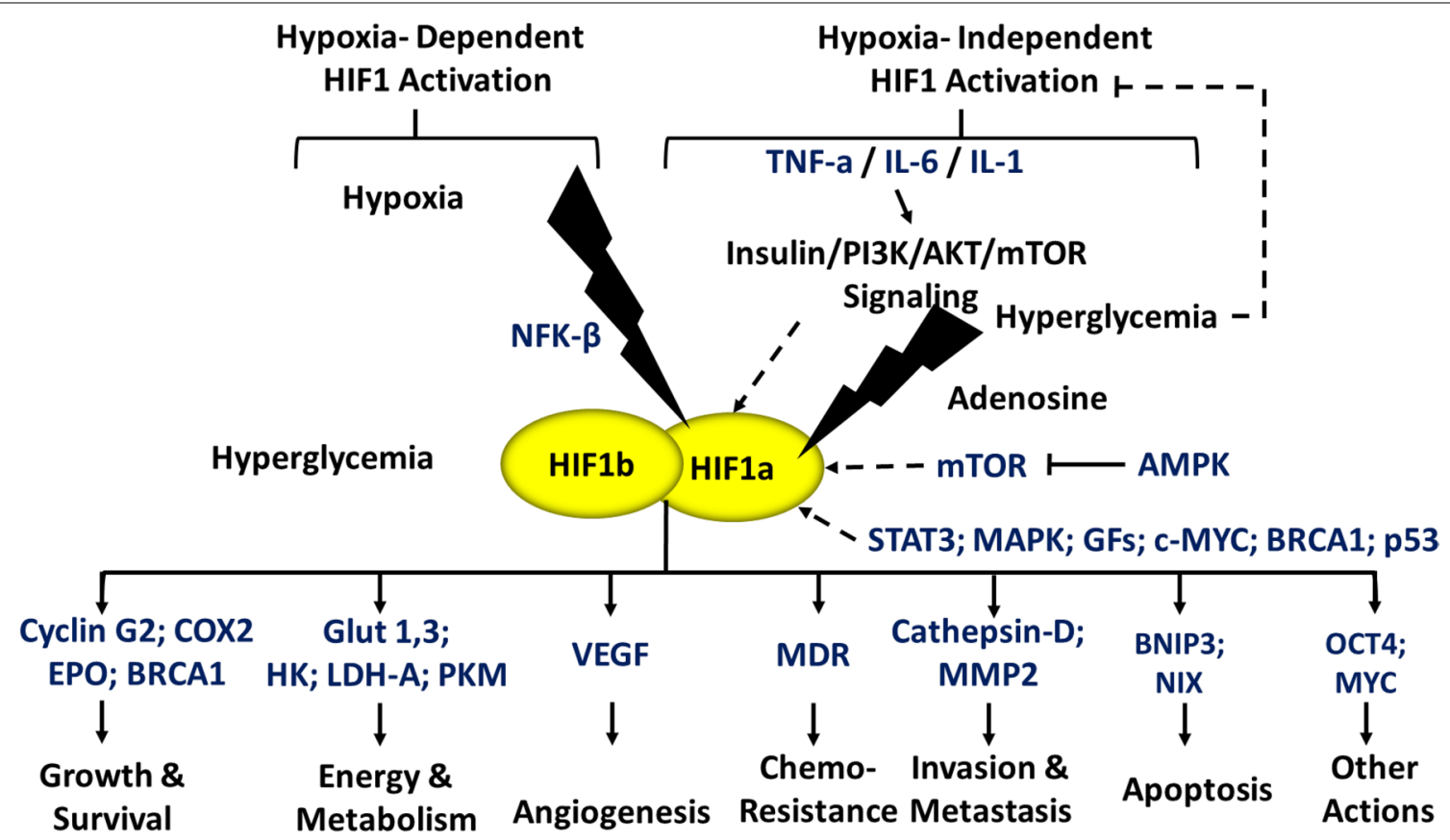

Fig. 3 HIF1 signaling. HIF1 is a dimeric transcription factor composed of an oxygen concentration sensitive HIF1-a subunit and a constitutively present HIF1- $\beta$ subunit. Under hypoxic conditions, HIF1-a stabilizes and forms a dimer with HIF1- $\beta$ subunit to transcriptionally activate the expression of HIF1 target genes. HIF1 has also been shown to be activated under normoxic conditions by various factors as depicted [108-116]

\section{Pathways that crosstalk}

Cancer being a complex phenomenon involves an intricate merger of various signaling cascades including but not limited to the pathways already discussed, yet this paper aims to elucidate on the central role of HIF1 signaling in mediating the crosstalk and disease state. Tracing its role in diabetes may give insight into the molecular basis for diabetes-associated breast carcinogenesis.

Hence, key players of the diabetes- breast cancer crosstalk include insulin and its binding to insulin receptor which triggers the insulin pathway, and which subsequently leads to the activation of PI3K-AKT and MAPK pathways, and HIF1 signaling via mTOR pathway [124]. Hypoxia is also shown to activate the AKT pathway [106]. HIF1 signaling up regulates GLUT1 and GLUT3 which in turn regulates metabolism, VEGF, which controls angiogenesis and hence contributes to cell survival, and also lead to the activation of c-Myc and IGF2, along with other genes which promote cell proliferation as shown in Fig. 4.

An intricate crosstalk between HIF1 signaling and other key players including breast cancer specific markers estrogen and HER2, and other cell survival and proliferation markers may mediate the hallmarks of transition from diabetic to comorbid state.

\section{Hallmarks of diabetes and breast cancer Hyperglycemia and its complications}

Hyperglycemia is a term used for high blood glucose level, caused either by a lack of insulin secretion or its inaction [129]. It is a characteristic of diabetes, but has also been reported in non-diabetic acute illness. It is also considered a physiological response to inflammation, and leads to an increased production of cytokines such as NF- $\mathrm{B}$ B and c-reactive protein (CRP) [130].

Hyperglycemia is a risk factor for cancer progression as it has shown to lead to tumor growth. However, the underlying molecular mechanism is not fully understood, yet there are several ways through which hyperglycemia contributes to tumor progression. This includes the up-regulation of glucose transporters such as GLUT1 and GLUT3, and growth factors, which contribute to cancer cell proliferation. Glucose metabolism leads to advanced glycation products (AGEs) and their interaction with receptors (RAGEs), ultimately leading to increased oxidative stress, contributing to DNA damage and genomic instability. Hence the role of hyperglycemia is well established in linking the metabolic nature of both diabetes and breast cancer. 


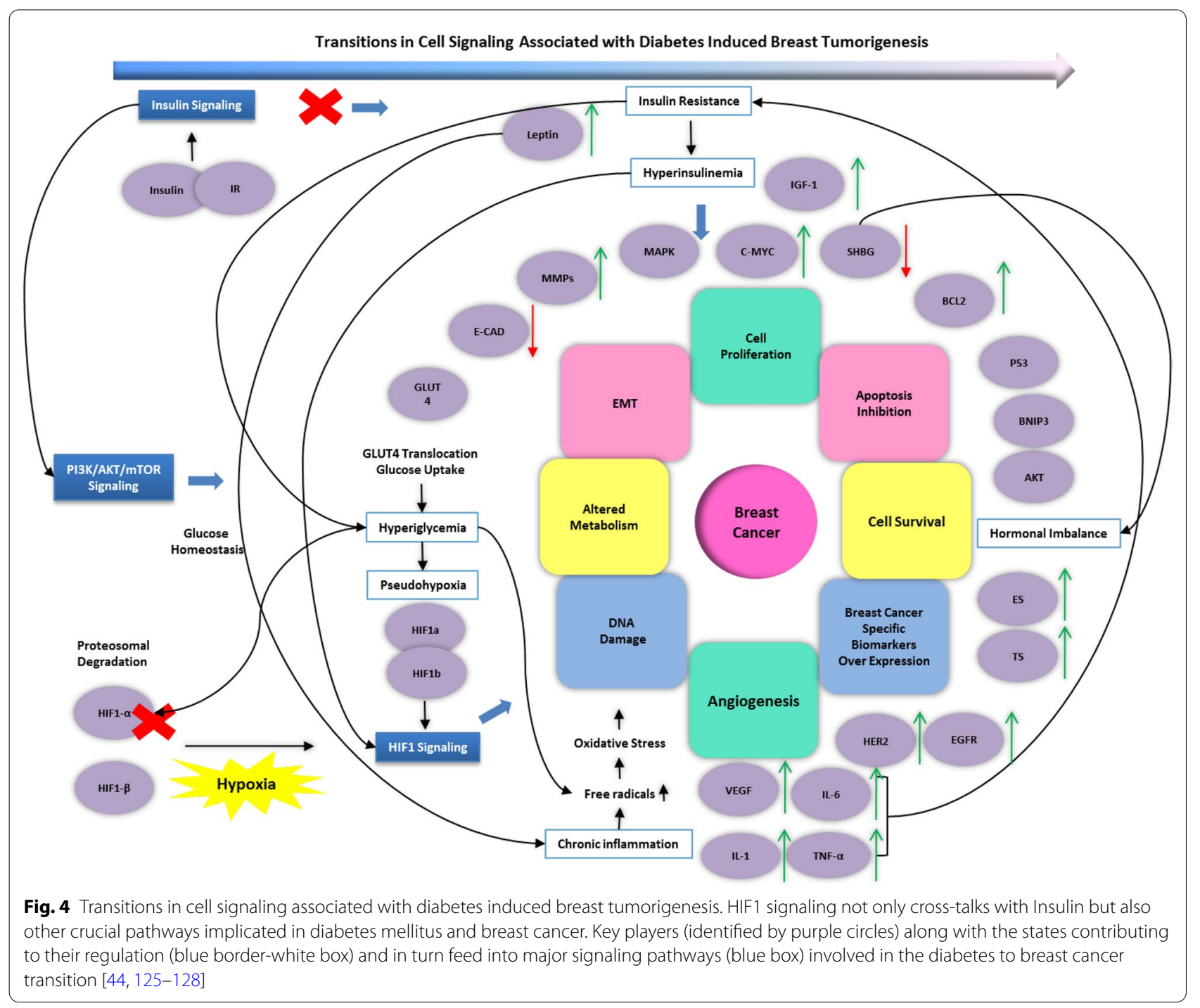

\section{Hypoxia induction and its aftermath}

Hypoxia is the state of inadequacy of oxygen in a tissue due to any reason [131]. Increasing evidence highlights its role in multiple diseases and metabolic disorders such as diabetes [132], and cancer [133, 134]. Hypoxia, along with other conditions such as inflammation, ERstress and mitochondrial dysfunction, are all associated with insulin resistance, which is a characteristic of type 2 diabetes.

Notably, it is one of the major contributing factors to tumor malignancy. The extent and time of exposure to hypoxia, partially determines the cancer cell's response to it; whether it leads to cell death or cell survival via triggering autophagic pathways. Prolonged hypoxia leads to increased ROS production, which promotes tumor cell survival and progression.

\section{The hypoxia-hyperglycemia axis}

Hyperglycemia reportedly induces hypoxic conditions and generation of mitochondrial ROS. Low oxygen levels stabilize HIF1- $\alpha$ subunit, which then binds with the beta subunit to mediate cell's coordinated response to hypoxia.

It is already known that hyperglycemia and hypoxia interact via common mechanisms to cause complications in diabetic patients. Both the conditions have shown to promote glycolysis, however via independent pathways and these effects are shown to be additive in causing diabetic retinopathy [135]. Hypoxia also reportedly decreases insulin signaling in adipocytes [136].

Additionally, high glucose level in breast cancer patients has been associated with elevated IGFBP2 levels and subsequently with chemo-resistance, highlighting the role of IGFBP2 in modulating a cancer cell's 
response to chemotherapy. Since T2DM is characterized by hyperglycemia, the potential role of IGFBP2 in T2DM induced breast cancer, and particularly as a therapeutic target to increase chemo-sensitivity of breast cancer cells seems plausible. Under the hypoxia-hyperglycemia equation, hypoxic conditions have shown to correspond with reduced IGFBP2 levels, consequently negating the chemo-resistant effects of hyperglycemia [137]. However, further research is necessary to fully understand the molecular nature of IGFBP2's role in chemo-resistance, particular within the hypoxia-hyperglycemia crosstalk.

Furthermore, hyperglycemia may also activate HIF1 via mTOR signaling [138]. Hence, it is crucial to understand the crosstalk fully, specifically the impact of hyperglycemia on HIF1 pathway in breast cancer cells, in order to determine the molecular basis of diabetes-breast cancer link. This may be possible by applying a mechanistic approach to identifying potential biomarkers such as HIF1 that could crucially determine and regulate mutual aberrations in both diabetes and breast cancer and how pre-morbiditic diabetic state may progress into a mammary cancerous state.

\section{Hyperinsulinemia}

Increased phosphorylation of IRS proteins prevents tyrosine phosphorylation leading to insulin resistance [139], which leads to compensatory hyperinsulinemia. Moreover, high insulin level is independently associated with breast carcinogenesis and progression, and this is supported by reports of insulin overexpression in breast cancer cells [140]. Once it binds to its receptor, it activates cell-signaling leading to cell survival, increased glucose uptake, mitogenesis, cell proliferation, invasion, and metastasis [30]. Besides, its direct mitogenic effects, it induces the expression of other factors including IGF-1 and HIF-1 [141], and increases bioavailability of estrogen [142].

\section{Chronic inflammation}

Increased production of cytokines and adipokines particularly by the adipose tissue in diabetic state may provide a favorable microenvironment for breast tumor growth. Specifically, interleukin-6 (IL-6), may lead to the activation of the JAK-STAT pathway, which not only enhances cell survival and proliferation, but also inhibits host anti-tumorigenic immune response [143]. Interestingly, HIF1 yet again plays a central role in mediating a connection between inflammatory response and carcinogenesis. It promotes the recruitment of immune cells and positively regulate the function of pro-tumorigenic inflammatory response cells [144], forming yet another molecular bridge between T2DM and breast cancer.

\section{Hormonal imbalances}

Besides the implication of the insulin/IGF-1 axis, diabetes involve the dysregulation of other hormones, which implicate HIF1 signaling and may promote breast carcinogenesis such as the adiponectin-leptin duo. In patients with obesity associated diabetes, elevated leptin levels lead to increased aromatase and estrogen production, release of pro-inflammatory cytokines, cell proliferation, migration and invasion [145]. This coupled with low levels of anti-tumorigenic adiponectin facilitate tumor progression [146].

\section{HIF1's regulation of the multilayered, relationship between T2DM and breast cancer Multilayers within the T2DM-BC association}

The complex nature of the association between diabetes and breast cancer becomes evident, as T2DM not only affects breast cancer risk but also its prognosis, besides an independent link between diabetic treatment and breast cancer risk and prognosis. Conversely, breast cancer has also been associated with the development of T2DM, and there are reports of cancer medication inducing T2DM characteristics in patients, as detailed in this section.

\section{T2DM and breast cancer risk}

T2DM is associated with a $20 \%$ increased breast cancer risk. However, the discrepancy in the status of HIF1 expression in diabetic patients needs to dealt with further research to elaborate on its potential diagnostic and predictive role as a biomarker for breast cancer patients with diabetes.

There are reports of associating diabetes with breast cancer, positively correlating it with ER expression negative status, however the results are conflicting, and further studies are required to clarify on this [66].

\section{T2DM and $B C$ prognosis}

Breast cancer patients with pre-existing diabetes have an overall worse prognosis and decreased survival. Literature has shown that the therapeutically enhanced expression of HIF1 in diabetic patients may help alleviate diabetic complications. However, there are also reports of HIF1 targeting as a potentially effective strategy for targeting HIF1 mediated insulin resistance and treating diabetes [147]. This disparity in the comprehension of the role of HIF1 in diabetic pathogenesis raises the question of whether HIF1 targeting may be a potentially effective strategy in treating breast cancer complicated with 
diabetes. Although the significance of HIF1 targeting in breast cancer is well established, and is associated with overall improved survival, however, depleting HIF1 in breast cancer patients with diabetes may affect diabetic complications associated mortality in these patients, and may prove as an added health concern.

\section{T2DM treatment and $B C$}

As previously discussed, diabetic treatments report an independent association with breast cancer incidence and prognosis. The therapeutic use of insulin and its analogues in diabetic patients was shown to correlate with a higher incidence of breast cancer [71, 148], however these conflict with another study reporting the inhibitory effect of insulin on tumor growth [149]. Metformin targets PI3K-AKT pathway and AMPK reduces glucose level in diabetic patients, and is shown to exhibit antitumorigenic properties [150, 151]. For other glucose lowering drugs such as sulfonylureas and glinides, there is yet again inconsistency in published literature, hence requiring further investigation.

\section{$B C$ treatment and T2DM}

Conversely, there are certain breast cancer treatments including temsirolimus and everolimus, which target tyrosine kinases, and lead to the development of hyperglycemic condition characteristic of diabetes [152]. Additionally, anti-neoplastic glucocorticoids are also prescribed as adjuvant therapy, which induce diabetes [150].

Herbal extracts such as the common sage (Salvia Officialis) extract have also reported anti-hyperglycemic, anti-inflammatory and anti-proliferative activities and hence may potentially be effective against treating breast cancer complicated with T2DM or diabetes induced breast cancer [153]. However, future studies are required to further elucidate on its therapeutic efficacy in co-morbid state.

\section{HIF1 expression in type 2 diabetes mellitus}

There are numerous reports of hyperglycemic conditions destabilizing HIF1- $\alpha$ level, associating it to diabetic complications such as impaired wound healing [154-156]. This is consistent with the report of HIF1- $\alpha$ expression up-regulation in diabetic mice ameliorating wound healing and angiogenesis, elucidating on the prognostic advantage of restoration of HIF1- $\alpha$ expression in diabetic state. Additionally, down-regulated HIF1 expression in diabetic foot ulcer, exposed to hypoxic but not hyperglycemic condition, was also reported [157]. The status of HIF1 expression, directly regulating VEGF level, is also associated with vasculature response, and its impairment may translate into vasculature-associated complications in diabetic patients [158]. The effect of hyperglycemia on
HIF1- $\alpha$ level was further investigated and it was found that glucose affected HIF1 expression only under hypoxic conditions in human dermal fibroblasts (HDF).

Furthermore, the knockdown of HIF1 in adipocytes resulted in increased insulin secretion leading to increased glucose tolerance and amelioration of insulin resistance, establishing its potential as a promising T2DM therapeutic target [159, 160]. This is supported by the role HIF1 plays in inflammation response leading to insulin resistance in adipose tissue [147].

Contrary to this, HIF1 is stabilized by both insulin and IL-1, which are overexpressed in diabetes under normoxic condition $[138,161,162]$. PI3K-AKT pathway activated by hypoxia and crucial to insulin signaling is also implicated in the stabilization and accumulation of HIF1, which in turn has a positive impact on insulin sensitivity and glucose metabolism in skeletal tissue [163]. Hence, there may be tissue specific signaling determining the influence of HIF1 in diabetic state and further research may shed light into the cell type specific expression status of HIF1 in T2DM.

\section{HIF1 expression in breast cancer subtypes}

Further broadly categorizing breast cancer subtypes as outlined in Fig. 2, based on hormone expression status, three main categories emerge, hormone expressing, HER2 expressing and triple negative breast cancer (TNBC), with the TNBC subtype being most aggressive. A study conducted in 2019, reported a higher TNBC and HER2 expressing breast cancer specific increased risk in diabetic patients, particularly for TNBC, which expresses higher IGF level [66], along with long-term metformin usage particularly associated with increased odds of developing TNBC.

Relating to the reported HIF1 expression across these breast cancer subtypes, may provide insight into the subtype specific potential of HIF1 as a therapeutic target. Tumor hypoxia and HIF1 expression is associated with tamoxifen resistance and overall poorer prognosis in estrogen receptor positive breast cancer [164]. HER2 overexpressing breast cancer cells reportedly stabilized HIF1 levels under normoxic conditions, highlighting at its role in HER2 breast cancer specific signaling [165]. Similarly, increased HIF1 expression in TNBC is associated with more aggressive phenotype, hence necessitating the therapeutic targeting of HIF1 to enhance disease prognosis [166].

\section{Breast cancer subtype specific signaling}

The molecular signaling underlying different breast cancer subtypes may implicate common and differential signaling pathways. The up-regulation of insulin and IGF is particularly higher in TNBC relative to those in the 
estrogen responsive cells, and which may then lead to HIF1 activation [167]. Similarly, cytokines such as IL-6 and IL-8 are implicated in tumor growth and evading apoptosis in TNBC but not in ER-positive breast cancer cells [168].

Hormone expressing subtypes express ER and/or PR, HER2 enriched breast cancer overexpress HER2 whereas TNBC do not express ER, PR and HER2. Estrogen, HER2 and EGFR signaling pathways once turned on in different breast cancer subtypes, activate common downstream signaling pathways such as PI3K-AKT and MAPK/ERK pathways which then mediate the hallmarks of cancer.

\section{HIF1-a's mediation of T2DM-BC Association}

Increased HIF1 expression is associated with overall poorer survival in breast cancer patients [169], and several studies directly or indirectly implicate HIF1- $\alpha$ in the diabetes-breast cancer crosstalk. A study conducted in 2015, reported HIF1 mediated advancement of breast metastasis in comorbid patients [170], however the article cannot be fully reviewed, as it was excluded based on language discrepancy. Hence, to date, to the best of our knowledge, there has been very limited prior experimental study designed to potentiate the role of HIF1- $\alpha$ in diabetes-breast cancer crosstalk. Published in 2017, a study reported the induction of HIF1 expression by hyperinsulinemia mediated inhibition of HIF1- $\alpha$ ubiquitination, in estrogen receptor positive breast cancer cells derived from breast tumor in T2DM mice [171]. HIF1, once activated, may promote tumorigenic activities leading to the initiation and progression of breast cancer in subjects with diabetes, hence potentiating the role of HIF1-insulin axis in T2DM-BC crosstalk, since, both T2DM and breast cancer are characterized by hypoxia state.

Furthermore, insulin also leads to the activation of leptin, an obesity related hormone, already known to associate with breast cancer progression via transcription factors including HIF1 and its crosstalk with PI3K-AKT and ERK1/2 pathways [172, 173].

Additionally, tumor microenvironment consists of cells including adipocytes [174], which synthesize bioactive molecules including growth factors, estrogen, and leptin, exposing mammary tissue to pro-tumorigenic factors [175]. Leptin activates the JAK-STAT breast cancer pathway leading to c-MYC and BCL2 expression mediated cell growth and proliferation $[176,177]$, whereas estrogen may regulate the development of estrogen dependent breast cancers [178]. Leptin also leads to HIF1 mediated increased expression of aromatase, which is required for estrogen signaling.

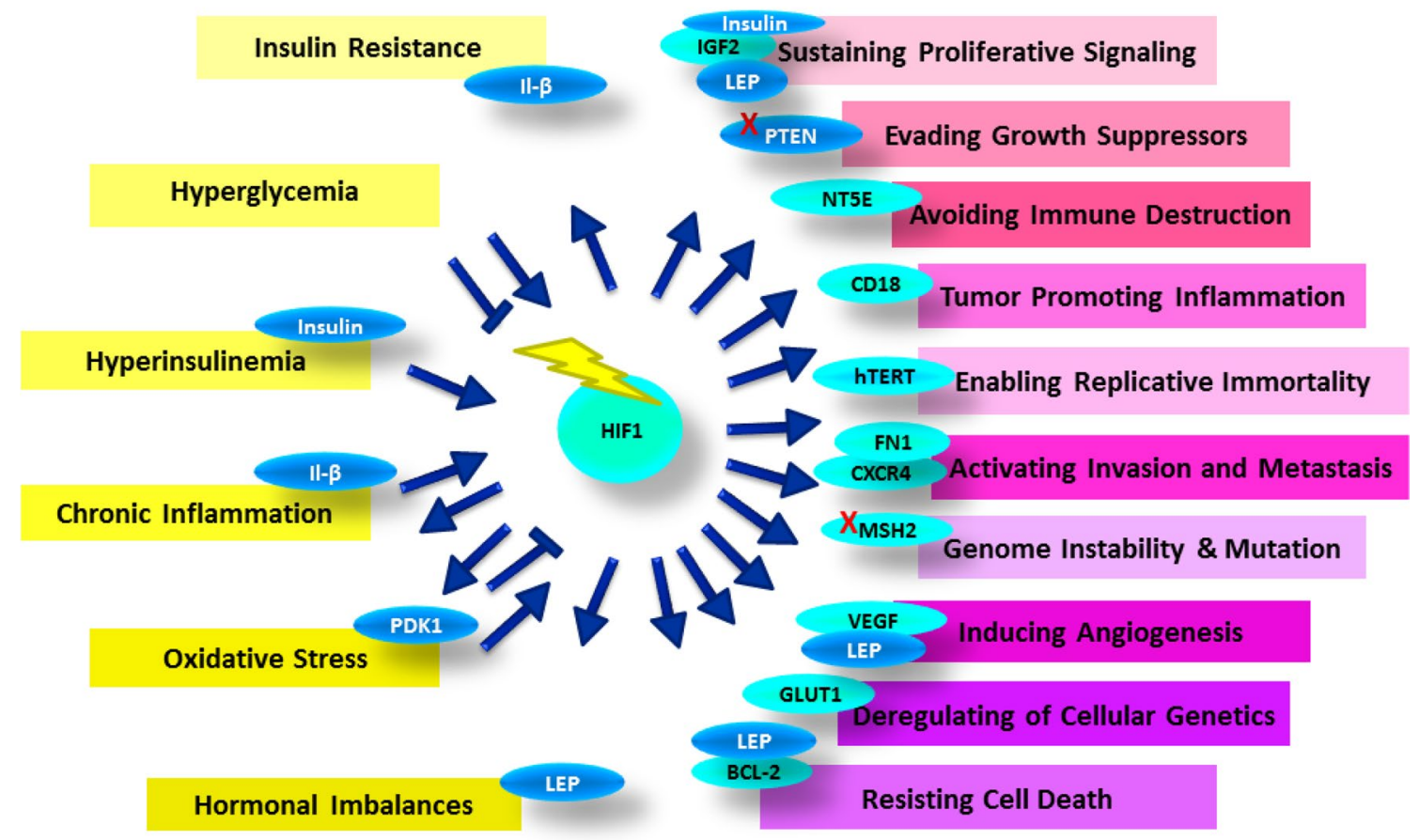

Fig. 5 HIF-1 relaying crosstalk between T2DM and breast cancer hallmarks. It is regulated by hyperinsulinemia, hyperglycemia and other hallmarks of diabetes and once activated, it mediates insulin resistance and other features of T2DM and hallmarks of breast cancer 
Obesity may also serve as a factor for breast cancer development, as the addition in adipose tissue composing the breast may promote the development of hypoxic conditions, inflammatory response and insulin resistance [179].

Hence, HIF1- $\alpha$ is intricately involved in mediating phenotypic characteristics of T2DM and breast cancer, and the T2DM-BC crosstalk, as annotated in Fig. 5.

The molecular alterations within the diabetic state may stabilize or destabilize HIF1 level. Once HIF1 is activated, it feedbacks into mediating diabetic hallmarks such as insulin resistance, oxidative stress and chronic inflammation. It relays the molecular crosstalk to mediate the development of hallmarks of cancer, directly via its target genes such as IGF2, CD18, VEGF, FN1, GLUT1 and BCL2 and indirectly by inducing other factors such as insulin, leptin and negatively regulating PTEN.

Additionally, several studies discuss the role of various therapeutic agents targeting diabetes and breast cancer, while also implicating HIF1- $\alpha$. Recently, there has been an emerging focus on studying the role of metformin, an anti-diabetic drug, as an anti-cancer therapeutic avenue [180]. It is being pursued for its potential to be repurposed as an anti-cancer drug [179], and associated with an overall reduced cancer risk in diabetic patients. It was shown to induce $\mathrm{p}$-AMPK mediated prolyl hydroxylases (PHDs) expression in cancer-associated fibroblasts, a major constituent of the tumor microenvironment, leading to HIF1 inhibition and subsequently decreased breast cancer invasion. Hence, metformin's role in targeting pro-tumorigenic reprogramming in tumor microenvironment especially by modulating tumor-stromal crosstalk may be studied further. However, this may lead to the question of whether metformin would be an effective therapeutic strategy for co-morbid patients already expressing low HIF1 levels, in lieu that it may further aggravate diabetic complications. Hence, further research is necessary to understand this.

Additionally, a microRNA, miR-18a has been implicated in diabetes- breast cancer crosstalk and it reportedly target HIF1- $\alpha$ [181, 182], and YC-1 is a specific HIF1- $\alpha$ signaling inhibitor by blocking HIF1- $\alpha$ synthesis [183].

Another study, conducted in 2012, showed the increased expression of HIF1 in co-morbid patients, and which significantly decreased in response to metformin treatment [184]. Where hyperglycemia is shown to destabilize HIF1 levels, there are also reports of targeting HIF1 leading to amelioration of obesity and insulin resistance, further elaborating on its potential as therapeutic agent [160].

Metformin, derived from biguaide, is a first line T2DM oral treatment, as prescribed by America
Diabetes Association (ADA) [185]. Recent evidence is emerging on its potential role as an anti-cancer therapeutic; however the underlying mechanism for this property is not fully understood. It is also shown to inhibit HER2 mediated cell proliferation and angiogenesis via targeting of HIF1 and its downstream transcriptional activation of VEGF, a master regulator of angiogenesis [186].

Furthermore, metformin is also reported to promote AMPK signaling mediated apoptosis in breast cancer cells and white adipose tissue endothelial cells [187], which have been shown to play a cooperative role in breast cancer angiogenesis and metastasis, hence modulating both the tumor and its microenvironment, specifically in TNBC and HER2 positive breast cancer cells.

Another anti-diabetic drug shown to possess antitumorigenic property is rhaponticin (RA), derived from medicinal herbs [188]. It was shown to suppress angiogenesis, metastasis and resistance to apoptosis in breast cancer cell line MDA-MB-231, derived from TNBC, via targeting the HIF1 signaling pathway.

Additionally, dacosahexaenoic acid is a type of omega-3 polyunsaturated fatty acid, which is reported to not only be effective for diabetes, but also for cancer with its anti-proliferative, anti-angiogenesis, anti-invasion, anti-metastatic and pro-apoptotic properties, via negatively regulating HIF1- $\alpha$ levels, leading to downregulation of glycolytic enzymes in breast cancer cells [189].

\section{Targeting HIF1 in T2DM-breast cancer patients dilemma}

Disparity in findings reporting HIF1 expression in diabetic patients creates a need for further research on its cell type specific expression, to enable HIF1 expression based patient selection in breast cancer patients with T2DM before opting for HIF1 targeting as a therapeutic strategy. To this end, we propose a scheme as shown in Fig. 6, suggesting considerations for devising therapeutic strategy for diabetic, breast cancer and comorbid patients. While targeting of HIF1 may tackle with breast cancer and diabetes associated worse prognosis, the application of combination therapy such as the addition of VEGF expression enhancers may prevent the implications of diabetic complications that may accompany the therapeutic down-regulation of HIF1 in patients with both T2DM and breast cancer.

HIF1 targeting in co-morbid patients may complicate diabetic prognosis further, hence combination therapy to treat diabetic complications alongside HIF1 targeting may be necessary. Similarly, for high HIF1- $\alpha$ expression in T2DM patients at risk of developing BC, HIF1 


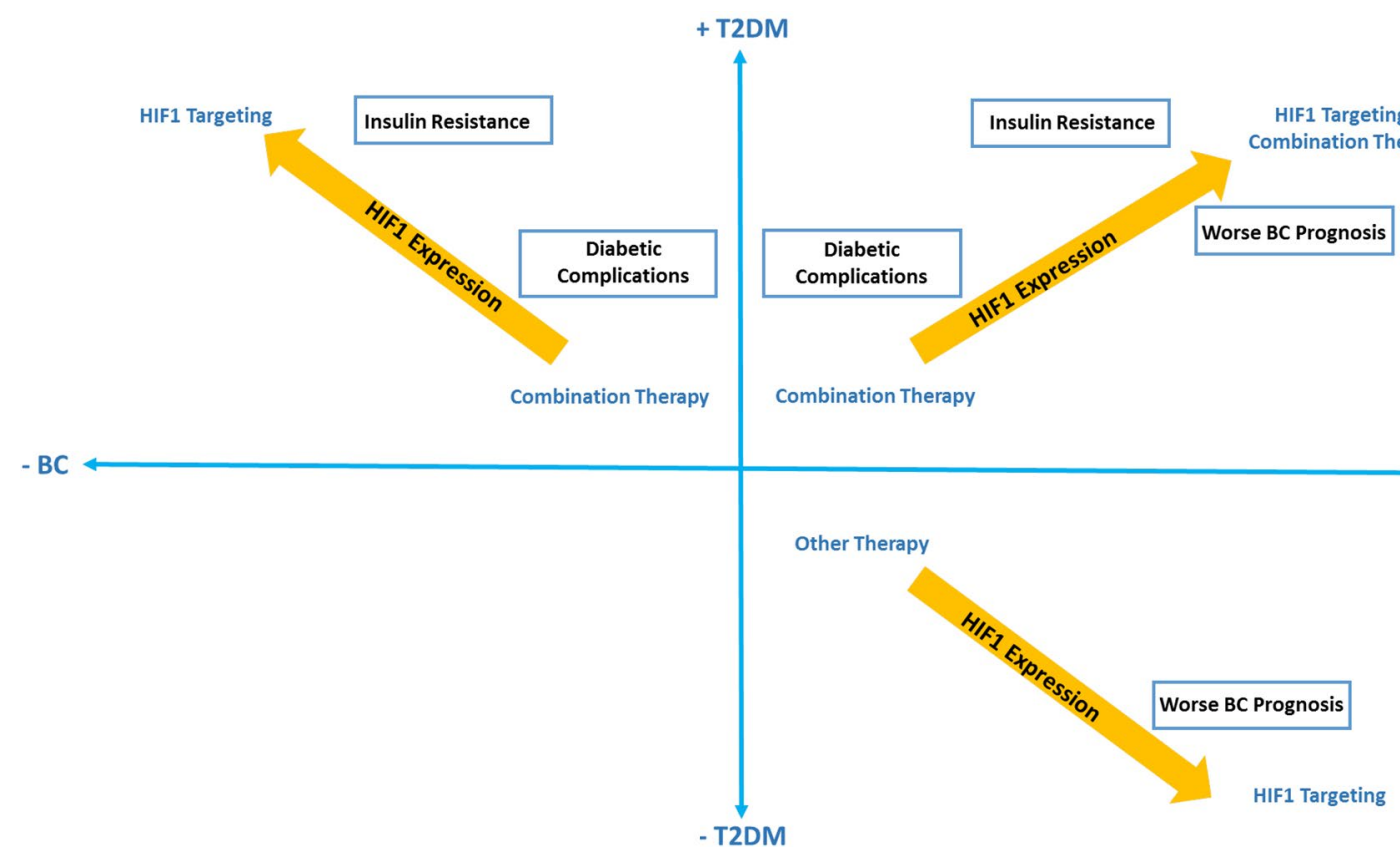

Fig. 6 Proposed scheme for devising a therapeutic strategy for T2DM-breast cancer patients

targeting may prove a promising therapeutic strategy, whereas for BC patients at risk of developing T2DM, HIF1 targeting may potentially alleviate disease prognostic outcome. However, in patients deficient in HIF1- $\alpha$ expression, other therapeutic strategies may need to be opted for.

\section{Initiation and progression of breast cancer}

The transformation of a normal cell into a malignant cancer cell involves a series of complex changes including initiation, promotion and progression [190]. There are numerous factors that could trigger and facilitate this transformation which include but are not limited to diet, prolonged exposure to carcinogens and obesity [191]. Increasing evidence has been associating diabetes, particularly T2DM with cancer risk, development, prognosis and even treatment [192] and T2DM is being established as a risk factor for cancer development. Hyperglycemia related complications are increasingly prevalent in cancer patients indicating at the role it may play in progressing cancer.

At molecular level, hyperglycemia and insulin mediated HIF1 signaling activation favors the development of hallmarks of cancer with the transforming cell. HIF1 target genes such VEGF promotes angiogenesis, GLUT1 and PDK-1 mediates metabolic shift to anaerobic metabolism [193], BCL2 regulates anti-apoptotic behavior and MMPs orchestrate epithelial to mesenchymal transition. Within this tumor promoting micro-environment, the build-up of ROS triggers DNA damage [194], and coupled with this, HIF1 also mediates inflammation promoting activities $[195,196]$. In synergy with all these molecular changes, insulin-IGF duo pushes the cell toward proliferation.

\section{Conclusion}

Hypoxia inducible factor 1 is a master regulator of hypoxia mediated cell response including alterations in the metabolic pathways particularly involving glucose uptake and its metabolism, and can be activated under non-hypoxic conditions. Its mediation of hallmarks of diabetes and breast cancer highlights its centrality to the molecular interplay between these two complex diseases and in governing the associated molecular players establishing the molecular connections between diabetes and breast cancer. This potentiates its relevance as a biomarker with prognostic and therapeutic significance, however there is very limited research done on this and further experimentation is required to fully comprehend the role of HIF1 in comorbid state.

Furthermore, it is also paramount to consider the implication of targeting HIF1 expression, which, although it may alleviate prognosis of breast cancer, and diabetes associated insulin resistance, yet may still translate into 
diabetic complications particularly those vasculature in nature, and worsen the overall survival outcome. Hence, there is a need to consider expression levels of potential prognostic markers such as HIF1 in comorbid patients, to ensure a more effective therapeutic strategy against breast cancer complicated with diabetes. Combination therapy such as VEGF expression enhancers may be prescribed to patients selected for HIF1 targeting therapy, to prevent diabetic complications associated mortality in breast cancer patients. While, targeting HIF1 and other associated potential biomarkers may in fact reduce mortality associated with breast cancer in diabetic patients, eventually alleviating the socioeconomic burden of diabetes- breast cancer association on global health.

\section{Abbreviations}

HIF 1: Hypoxia inducible factor 1;T2DM: Type 2 diabetes mellitus; TNF-a: Tumor necrosis factor- al pha; IGF: Insulin-like growth factor; PI3K: Phosphatidylinositol-3-kinase; mTOR: The mammalian target of rapamycin;T1DM: Type 1 diabetes mellitus; IRS: Insulin receptor substrate; MAPK: Mitogenactivated protein kinase; PHD: Prolyl hydroxylase; FIH1: Factor inhibiting HIF-1; ERK: Extracellular-signal-regulated kinase; IL: Interleukin; GLUT: Glucose transporter; NF-KB: Nuclear factor kappa-light-chain-enhancer of activated B cells; GSK: Glycogen synthase kinase; MMP: Matrix metallo-peptidase; BNIP3: BCL2/adenovirus E1B $19 \mathrm{kDa}$ protein-interacting protein 3; VEGF:Vascular endothelial growth factor; AMPK 5': AMP-activated protein kinase; STAT3: Signal transducer and activator of transcription 3; GF: Growth factor; MYC: Master regulator of cell cycle entry and proliferative metabolism; BRCA1: Breast cancer protein 1; COX2: Cyclooxygenase 2; EPO: Erythropoietin; HK: Hexokinase; LDH-A: Lactate dehydrogenase A; PKM: Pyruvate kinase muscle isozyme; MDR: Multi-drug resistance protein; OCT4: Octamer-binding transcription factor 4; ECAD: E-cadherin; SBHG: Sex hormone binding globin; BCL2: B-cell lymphoma 2; ES: Estrogen; TS: Testosterone; IR: Insulin receptor; CRP: C-reactive protein; ROS: Reactive oxygen species.

\section{Acknowledgements}

Not applicable.

\section{Authors' contributions}

All authors contributed to conceptualizing, drafting and reviewing this manuscript. All authors read and approved the final manuscript.

\section{Funding}

Not applicable.

\section{Availability of data and materials}

Not applicable.

\section{Declarations}

Ethics approval and consent to participate

Not applicable.

\section{Consent for publication}

All authors consent to publishing this article.

\section{Competing interests}

The authors declare that there are no competing interests.

Received: 13 October 2020 Accepted: 24 June 2021

Published online: 05 July 2021
References

1. Habib SL, Rojna M. Diabetes and risk of cancer. ISRN Oncol. 2013;2013:583786.

2. Abudawood M. Diabetes and cancer: a comprehensive review. J Res Med Sci. 2019;24:94

3. Zhou B, Lu Y, Hajifathalian K, Bentham J, Di Cesare M, Danaei G, et al. Worldwide trends in diabetes since 1980: a pooled analysis of 751 population-based studies with 4.4 million participants. Lancet. 2016;387:1513-30.

4. Vos T, Barber RM, Bell B, Bertozzi-Villa A, Biryukov S, Bolliger l, et al. Global, regional, and national incidence, prevalence, and years lived with disability for 301 acute and chronic diseases and injuries in 188 countries, 1990-2013: a systematic analysis for the Global Burden of Disease Study 2013. Lancet. 2015;386:743-800.

5. Bray F, Ferlay J, Soerjomataram I, Siegel RL, Torre LA, Jemal A. Global cancer statistics 2018: GLOBOCAN estimates of incidence and mortality worldwide for 36 cancers in 185 countries. Cancer J Clin. 2018;68:394-424.

6. Wojciechowska J, Krajewski W, Bolanowski M, Kręcicki T, Zatoński T. Diabetes and cancer: a review of current knowledge. Exp Clin Endocrinol Diabetes. 2016;124:263-75.

7. Kahanovitz L, Sluss PM, Russell SJ. Type 1 diabetes-a clinical perspective. Point Care. 2017;16:37.

8. De Fronzo RA, Ferrannini E, Groop L, Henry RR, Herman WH, Holst JJ, et al. Type 2 diabetes mellitus. Nat Rev. 2015;1:1-22.

9. Hoadley KA, Yau C, Hinoue T, Wolf DM, Lazar AJ, Drill E, et al. Cell-oforigin patterns dominate the molecular classification of 10,000 tumors from 33 types of cancer. Cell. 2018;173:291-304.

10. Idikio HA. Human cancer classification: a systems biology-based model integrating morphology, cancer stem cells, proteomics, and genomics. J Cancer. 2011:2:107.

11. Ben Q, Xu M, Ning X, Liu J, Hong S, Huang W, et al. Diabetes mellitus and risk of pancreatic cancer: a meta-analysis of cohort studies. Eur J Cancer. 2011:47:1928-37.

12. Wang C, Wang X, Gong G, Ben Q, Qiu W, Chen Y, et al. Increased risk of hepatocellular carcinoma in patients with diabetes mellitus: a systematic review and meta-analysis of cohort studies. Int J Cancer. 2012;130:1639-48.

13. Friberg E, Orsini N, Mantzoros CS, Wolk A. Diabetes mellitus and risk of endometrial cancer: meta analysis. Meta Anal. 2007;50(7):1365-74.

14. Jiang Y, Ben Q, Shen H, Lu W, Zhang Y, Zhu J. Diabetes mellitus and incidence and mortality of colorectal cancer: a systematic review and meta-analysis of cohort studies. Eur J Epidemiol. 2011;26:863-76.

15. Larsson SC, Orsini N, Brismar K, Wolk A. Diabetes mellitus and risk of bladder cancer: a meta-analysis. Diabetologia. 2006;49:2819-23.

16. Larsson SC, Mantzoros CS, Wolk A. Diabetes mellitus and risk of breast cancer: a meta-analysis. Int J Cancer. 2007;121:856-62.

17. García-Jiménez C, Gutiérrez-Salmerón M, Chocarro-Calvo A, GarcíaMartinez JM, Castaño A, De la Vieja A. From obesity to diabetes and cancer: epidemiological links and role of therapies. Br J Cancer. 2016;114:716-22.

18. Boyle P, Boniol M, Koechlin A, Robertson C, Valentini F, Coppens K, et al. Diabetes and breast cancer risk: a meta-analysis. Br J Cancer. 2012;107:1608-17.

19. Bowker SL, Majumdar SR, Veugelers P, Johnson JA. Increased cancerrelated mortality for patients with type 2 diabetes who use sulfonylureas or insulin. Diabetes Care. 2006;29:254-8.

20. Monami M, Lamanna C, Pala L, Bardini G, Cresci B, Francesconi P, et al. Treatment with insulin secretagogues and cancer-related mortality in type 2 diabetic patients a retrospective cohort study. Exp Clin Endocrinol Diabetes. 2008;116:184-9.

21. Currie CJ, Poole CD, Gale EAM. The influence of glucose-lowering therapies on cancer risk in type 2 diabetes. Diabetologia. 2009;52:1766-77.

22. Hemkens LG, Grouven U, Bender R, Günster C, Gutschmidt S, Selke GW, et al. Risk of malignancies in patients with diabetes treated with human insulin or insulin analogues: a cohort study. Diabetologia. 2009;52:1732-44.

23. Baur DM, Klotsche J, Hamnvik O-PR, Sievers C, Pieper L, Wittchen H-U, et al. Type 2 diabetes mellitus and medications for type 2 diabetes mellitus are associated with risk for and mortality from cancer in a German primary care cohort. Metabolism. 2011;60:1363-71. 
24. Van Staa TP, Patel D, Gallagher AM, De Bruin ML. Glucose-lowering agents and the patterns of risk for cancer: a study with the General Practice Research Database and secondary care data. Diabetologia. 2012;55:654-65.

25. Gristina V, Cupri MG, Torchio M, Mezzogori C, Cacciabue L, Danova M. Diabetes and cancer: a critical appraisal of the pathogenetic and therapeutic links. Biomed Rep. 2015;3:131-6.

26. Hanahan D, Weinberg RA. The hallmarks of cancer. Cell. 2000;100:57-70

27. Hanahan D, Weinberg RA. Hallmarks of cancer: the next generation. Cell. 2011;144:646-74.

28. Ferguson RD, Gallagher EJ, Scheinman EJ, Damouni R, LeRoith D. The epidemiology and molecular mechanisms linking obesity, diabetes, and cancer. Vitam Horm. 2013;93:51-98.

29. Rose DP, Vona-Davis L. The cellular and molecular mechanisms by which insulin influences breast cancer risk and progression. Endocr Relat Cancer. 2012;19:R225-41.

30. Giovannucci E, Harlan DM, Archer MC, Bergenstal RM, Gapstur SM, Habel LA, et al. Diabetes and cancer: a consensus report. Cancer J Clin. 2010;60:207-21

31. Ballotari P, Vicentini M, Manicardi V, Gallo M, Ranieri SC, Greci M, et al. Diabetes and risk of cancer incidence: results from a population-based cohort study in northern Italy. BMC Cancer. 2017;17:703.

32. Lawlor DA, Smith GD, Ebrahim S. Hyperinsulinaemia and increased risk of breast cancer: findings from the British Women's Heart and Health Study. Cancer Causes Control. 2004;15:267-75.

33. Vigneri P, Frasca F, Sciacca L, Pandini G, Vigneri R. Diabetes and cancer. Endocr Relat Cancer. 2009;16:1103-23.

34. Ryu TY, Park J, Scherer PE. Hyperglycemia as a risk factor for cancer progression. Diabetes Metab J. 2014;38:330-6.

35. Xiao H, Gu Z, Wang G, Zhao T. The possible mechanisms underlying the impairment of HIF-1 a pathway signaling in hyperglycemia and the beneficial effects of certain therapies. Int J Med Sci. 2013;10:1412-21.

36. Xiao Q, Zeng S, Ling S, Lv M. Up-regulation of HIF-1alpha and VEGF expression by elevated glucose concentration and hypoxia in cultured human retinal pigment epithelial cells. J Huazhong Univ Sci Technolog Med Sci. 2006;26:463-5.

37. Yan J, Zhang Z, Shi H. HIF-1 is involved in high glucose-induced paracellular permeability of brain endothelial cells. Cell Mol Life Sci. 2012;69:115-28.

38. Bensellam M, Duvillié B, Rybachuk G, Laybutt DR, Magnan C, Guiot Y, et al. Glucose-induced $\mathrm{O}_{2}$ consumption activates hypoxia inducible factors 1 and 2 in rat insulin-secreting pancreatic beta-cells. PLoS ONE. 2012;7:e29807.

39. Puri S, Cano DA, Hebrok M. A role for von Hippel-Lindau protein in pancreatic beta-cell function. Diabetes. 2009;58:433-41.

40. Isoe T, Makino Y, Mizumoto K, Sakagami H, Fujita Y, Honjo J, et al. High glucose activates HIF-1-mediated signal transduction in glomerular mesangial cells through a carbohydrate response element binding protein. Kidney Int. 2010;78:48-59.

41. Gallagher EJ, LeRoith D. Epidemiology and molecular mechanisms tying obesity, diabetes, and the metabolic syndrome with cancer. Diabetes Care. 2013;36:S233-9.

42. Nyholm H, Djursing H, Hagen C, Agner T, Bennett P, Svenstrup B. Androgens and estrogens in postmenopausal insulin-treated diabetic women. J Clin Endocrinol Metab. 1989;69:946-9.

43. Lipworth L, Adami H-O, Trichopoulos D, Carlström K, Mantzoros C. Serum steroid hormone levels, sex hormone-binding globulin, and body mass index in the etiology of postmenopausal breast cancer. Epidemiology. 1996;7:96-100.

44. Ferroni P, Riondino S, Buonomo O, Palmirotta R, Guadagni F, Roselli M. Type 2 diabetes and breast cancer: the interplay between impaired glucose metabolism and oxidant stress. Oxid Med Cell Longev. 2015;2015:183928.

45. Hwangbo Y, Lee EK. Acute hyperglycemia associated with anti-cancer medication. Endocrinol Metab. 2017;32:23-9.

46. Goodwin PJ, Ennis M, Pritchard Kl, Trudeau ME, Koo J, Madarnas Y, et al. Fasting insulin and outcome in early-stage breast cancer: results of a prospective cohort study. J Clin Oncol. 2002;20:42-51.

47. Irwin ML, Duggan C, Wang C-Y, Smith AW, McTiernan A, Baumgartner $\mathrm{RN}$, et al. Fasting C-peptide levels and death resulting from all causes and breast cancer: the health, eating, activity, and lifestyle study. J Clin Oncol. 2011;29:47.

48. James FR, Wootton S, Jackson A, Wiseman M, Copson ER, Cutress $\mathrm{RI}$. Obesity in breast cancer-what is the risk factor? Eur J Cancer. 2015;51:705-20.

49. Smid M, Wang Y, Zhang Y, Sieuwerts AM, Yu J, Klijn JG, et al. Subtypes of breast cancer show preferential site of relapse. Cancer Res. 2008;68:3108-14.

50. Sohail S, Alam SN. Breast cancer in Pakistan-awareness and early detection. J Coll Physicians Surg Pak. 2007;17(12):711-2.

51. Lipscombe LL, Goodwin PJ, Zinman B, McLaughlin JR, Hux JE. The impact of diabetes on survival following breast cancer. Breast Cancer Res Treat. 2008;109:389-95.

52. Louwman WJ, Janssen-Heijnen MLG, Houterman S, Voogd AC, Van Der Sangen MJC, Nieuwenhuijzen GAP, et al. Less extensive treatment and inferior prognosis for breast cancer patient with comorbidity: a population-based study. Eur J Cancer. 2005;41:779-85.

53. Yancik R, Wesley MN, Ries LA, Havlik RJ, Edwards BK, Yates JW. Effect of age and comorbidity in postmenopausal breast cancer patients aged 55 years and older. JAMA. 2001;285:885-92.

54. Michels KB, Solomon CG, Hu FB, Rosner BA, Hankinson SE, Colditz GA, et al. Type 2 diabetes and subsequent incidence of breast cancer in the Nurses' Health Study. Diabetes Care. 2003;26:1752-8.

55. Cleveland RJ, North KE, Stevens J, Teitelbaum SL, Neugut Al, Gammon MD. The association of diabetes with breast cancer incidence and mortality in the Long Island Breast Cancer Study Project. Cancer Causes Control. 2012:23:1193-203.

56. Griffiths RI, Danese MD, Gleeson ML, Valderas JM. Epidemiology and outcomes of previously undiagnosed diabetes in older women with breast cancer: an observational cohort study based on SEER-Medicare. BMC Cancer. 2012;12:613.

57. Zhang P-H, Chen Z-W, Lv D, Xu Y-Y, Gu W-L, Zhang X-H, et al. Increased risk of cancer in patients with type 2 diabetes mellitus: a retrospective cohort study in China. BMC Public Health. 2012;12:567.

58. Hardefeldt PJ, Edirimanne S, Eslick GD. Diabetes increases the risk of breast cancer: a meta-analysis. Endocr Relat Cancer. 2012;19:793.

59. Tabassum I, Mahmood H, Faheem M. Type 2 diabetes mellitus as a risk factor for female breast cancer in the population of Northern Pakistan. Asian Pac J Cancer Prev. 2016;17:3255-8.

60. Campbell PT, Newton CC, Patel AV, Jacobs EJ, Gapstur SM. Diabetes and cause-specific mortality in a prospective cohort of one million US adults. Diabetes Care. 2012;35:1835-44.

61. Zhao X-B, Ren G-S. Diabetes mellitus and prognosis in women with breast cancer: a systematic review and meta-analysis. Medicine. 2016;95:e5602.

62. Chavez-MacGregor M, Clarke CA, Lichtensztajn DY, Giordano SH. Delayed initiation of adjuvant chemotherapy among patients with breast cancer. JAMA Oncol. 2016;2:322-9.

63. Schrauder MG, Fasching PA, Häberle L, Lux MP, Rauh C, Hein A, et al. Diabetes and prognosis in a breast cancer cohort. Journal Cancer Res Clin Oncol. 2011;137:975-83.

64. Norwood P, Liutkus JF, Haber H, Pintilei E, Boardman MK, Trautmann ME. Safety of exenatide once weekly in patients with type 2 diabetes mellitus treated with a thiazolidinedione alone or in combination with metformin for 2 years. Clin Ther. 2012;34:2082-90.

65. Rattan R, Ali Fehmi R, Munkarah A. Metformin: an emerging new therapeutic option for targeting cancer stem cells and metastasis. J Oncol. 2012;2012:928127.

66. Chen H, Cook LS, Tang M-TC, Hill DA, Wiggins CL, Li Cl. Relationship between diabetes and diabetes medications and risk of different molecular subtypes of breast cancer. Cancer Epidemiol Biomark Prev. 2019:28:1802-8.

67. Chlebowski RT, McTiernan A, Wactawski-Wende J, Manson JE, Aragaki AK, Rohan T, et al. Diabetes, metformin, and breast cancer in postmenopausal women. J Clin Oncol. 2012;30:2844-52.

68. Palmer JR, Castro-Webb N, Bertrand K, Bethea TN, Denis GV. Type II diabetes and incidence of estrogen receptor negative breast cancer in African American women. Cancer Res. 2017;77:6462-9.

69. Roshan MH, Shing YK, Pace NP. Metformin as an adjuvant in breast cancer treatment. SAGE Open Med. 2019;7:2050312119865114. 
70. García-Esquinas E, Guinó E, Castaño-Vinyals G, Pérez-Gómez B, Llorca J, Altzibar JM, et al. Association of diabetes and diabetes treatment with incidence of breast cancer. Acta Diabetol. 2016;53:99-107.

71. Janghorbani M, Dehghani M, Salehi-Marzijarani M. Systematic review and meta-analysis of insulin therapy and risk of cancer. Horm Cancer. 2012;3:137-46.

72. Habel LA, Danforth KN, Quesenberry CP, Capra A, Van Den Eeden SK, Weiss NS, et al. Cohort study of insulin glargine and risk of breast, prostate, and colorectal cancer among patients with diabetes. Diabetes Care. 2013;36:3953-60.

73. Chang C-H, Lin J-W, Wu L-C, Lai M-S, Chuang L-M. Oral insulin secretagogues, insulin, and cancer risk in type 2 diabetes mellitus. J Clin Endocrinol Metab. 2012;97:E1170-1175.

74. Hsieh M-C, Lee T-C, Cheng S-M, Tu S-T, Yen M-H, Tseng C-H. The influence of type 2 diabetes and glucose-lowering therapies on cancer risk in the Taiwanese. Exp Diabetes Res. 2012;2012:413782.

75. Qiu H, Rhoads GG, Berlin JA, Marcella SW, Demissie K. Initial metformin or sulphonylurea exposure and cancer occurrence among patients with type 2 diabetes mellitus. Diabetes Obes Metab. 2013;15:349-57.

76. Shao S, Gill AA, Zahm SH, Jatoi I, Shriver CD, McGlynn KA, et al. Diabetes and overall survival among breast cancer patients in the US Military Health System. Cancer Epidemiol Prev Biomark. 2018;27:50-7.

77. Jo A, Scarton L, O'Neal LJ, Larson S, Schafer N, George TJ, et al. New onset of type 2 diabetes as a complication after cancer diagnosis: a systematic review. Cancer Med. 2021;10:439-46.

78. Lu L, Gan L, Hu J, Ran L, Cheng Q, Wang R, et al. On the status of $\beta$-cell dysfunction and insulin resistance of breast cancer patient without history of diabetes after systemic treatment. Med Oncol. 2014;31:956.

79. Lipscombe LL, Chan WW, Yun L, Austin PC, Anderson GM, Rochon PA. Incidence of diabetes among postmenopausal breast cancer survivors. Diabetologia. 2013;56:476-83.

80. Hamood R, Hamood H, Merhasin I, Keinan-Boker L. Diabetes after hormone therapy in breast cancer survivors: a case-cohort study. J Clin Oncol. 2018;36:2061-9.

81. Kim G, Yoo M, Hong MH, Lee B-W, Kang ES, Cha B-S, et al. Predictive factors for the development of diabetes in cancer patients treated with phosphatidylinositol 3-kinase inhibitors. Cancer Chemother Pharmacol. 2019:84:405-14

82. Yang S-P, Muo C-H, Wang I-K, Chang Y-J, Lai S-W, Lee CW-S, et al. Risk of type 2 diabetes mellitus in female breast cancer patients treated with morphine: a retrospective population-based time-dependent cohort study. Diabetes Res Clin Pract. 2015;110:285-90.

83. Probst-Hensch NM, Steiner JHB, Schraml P, Varga Z, Zürrer-Härdi U, Storz M, et al. IGFBP2 and IGFBP3 protein expressions in human breast cancer: association with hormonal factors and obesity. Clin Cancer Res. 2010;16:1025-32.

84. So Al, Levitt RJ, Eigl B, Fazli L, Muramaki M, Leung S, et al. Insulin-like growth factor binding protein- 2 is a novel therapeutic target associated with breast cancer. Clin Cancer Res. 2008;14:6944-54.

85. Association AD. Diagnosis and classification of diabetes mellitus. Diabetes care. 2014;37:S81-90.

86. Tripathi BK, Srivastava AK. Diabetes mellitus: complications and therapeutics. Med Sci Monitor. 2006;12:RA130-47.

87. Brännmark C, Nyman E, Fagerholm S, Bergenholm L, Ekstrand E-M, Cedersund $\mathrm{G}$, et al. Insulin signaling in type 2 diabetes experimental and modeling analyses reveal mechanisms of insulin resistance in human adipocytes. J Biol Chem. 2013;288:9867-80.

88. A.M. ElSharkawy. Breast Cancer. Principles and Practice of Cancer Prevention. CA: OMICS Group eBooks; 2014.

89. Kothari C, Diorio C, Durocher F. The importance of breast adipose tissue in breast cancer. Int J Mol Sci. 2020;21:5760.

90. Street W. Cancer Facts \& Figures 2019. Am Cancer Soc. 2018;76.

91. Kumar N, Patni P, Agarwal A, Khan MA, Parashar N. Prevalence of molecular subtypes of invasive breast cancer: a retrospective study. Med J Armed Forces India. 2015;71:254-8.

92. He L, LVY, Song Y, Zhang B. The prognosis comparison of different molecular subtypes of breast tumors after radiotherapy and the intrinsic reasons for their distinct radiosensitivity. Cancer Manag Res. 2019;11:5765.
93. Subbiah S, Gopu G, Senthilkumar P, Muniasamy P. Molecular subtypes as a predictor of response to neoadjuvant chemotherapy in breast cancer patients. Indian J Cancer. 2017;54:652.

94. Kuo S-H, Huang C-S. Association between radiosensitivity and molecular subtypes in patients with early-stage breast cancer and lymph node-negative status. 2017;S1462-6

95. Dai X, Li T, Bai Z, Yang Y, Liu X, Zhan J, et al. Breast cancer intrinsic subtype classification, clinical use and future trends. Am J Cancer Res. 2015:5:2929.

96. Seshie B, Adu-Aryee NA, Dedey F, Calys-Tagoe B, Clegg-Lamptey J-N. A retrospective analysis of breast cancer subtype based on ER/PR and HER2 status in Ghanaian patients at the Korle Bu Teaching Hospital, Ghana. BMC Clin Pathol. 2015;15:14.

97. Pérez-López ME, García-Gómez J, Alves MT, Paradela A, García-Mata J, García-Caballero T. Ki-67 is a prognostic marker for hormone receptor positive tumors. Clin Transl Oncol. 2016;18:996-1002.

98. Singhai R, Patil VW, Jaiswal SR, Patil SD, Tayade MB, Patil AV. E-Cadherin as a diagnostic biomarker in breast cancer. North Am J Med Sci. 2011;3:227.

99. Walsh MF, Nathanson KL, Couch FJ, Offit K. Genomic biomarkers for breast cancer risk. Novel Biomark Continuum Breast Cancer. 2016;885:1-32

100. Fröjdö S, Vidal H, Pirola L. Alterations of insulin signaling in type 2 diabetes: a review of the current evidence from humans. Biochimica et biophysica acta. 2009;1792:83-92.

101. Joshi S, Liu M, Turner N. Diabetes and its link with cancer: providing the fuel and spark to launch an aggressive growth regime. Biomed Res Int. 2015;2015:390863.

102. Boucher J, Kleinridders A, Kahn CR. Insulin receptor signaling in normal and insulin-resistant states. Cold Spring Harbor Perspect Biol. 2014:6:a009191.

103. Wang GL, Semenza GL. Purification and characterization of hypoxiainducible factor 1. J Biol Chem. 1995;270:1230-7.

104. Muz B, de la Puente P, Azab F, Azab AK. The role of hypoxia in cancer progression, angiogenesis, metastasis, and resistance to therapy. Hypoxia. 2015;3:83-92.

105. Haase VH. The sweet side of HIF. Kidney Int. 2010;78:10-3.

106. Stegeman H, Span PN, Peeters WJ, Verheijen MM, Grénman R, Meijer TW, et al. Interaction between hypoxia, AKT and HIF-1 signaling in HNSCC and NSCLC: implications for future treatment strategies. Future Sci. 2016;2:84.

107. Masoud GN, Li W. HIF-1a pathway: role, regulation and intervention for cancer therapy. Acta Pharmaceutica Sinica B. 2015;5:378-89.

108. Nagy MA. HIF-1 is the commander of gateways to cancer. J Cancer Sci Ther. 2011;3:35-40.

109. Ranasinghe WK, Baldwin GS, Bolton D, Shulkes A, Ischia J, Patel O. HIF1a expression under normoxia in prostate cancer-which pathways to target? J Urol. 2015;193:763-70.

110. Rohwer N, Zasada C, Kempa S, Cramer T. The growing complexity of $\mathrm{HIF-1a's} \mathrm{role} \mathrm{in} \mathrm{tumorigenesis:} \mathrm{DNA} \mathrm{repair} \mathrm{and} \mathrm{beyond.} \mathrm{Oncogene.}$ 2013;32:3569-76.

111. Mennerich D, Kubaichuk K, Kietzmann T. DUBs, Hypoxia, and Cancer. Trends Cancer. 2019;5(10):632-53.

112. Kang HJ, Kim HJ, Rih J-K, Mattson TL, Kim KW, Cho C-H, et al. BRCA1 plays a role in the hypoxic response by regulating HIF-1a stability and by modulating vascular endothelial growth factor expression. J Biol Chem. 2006:281:13047-56.

113. Wang J, Ni Z, Duan Z, Wang G, Li F. Altered expression of hypoxia-inducible factor-1a (HIF-1a) and its regulatory genes in gastric cancer tissues. PloS ONE. 2014;9:e99835.

114. Calvo-Asensio I, Dillon ET, Lowndes NF, Ceredig R. The transcription factor Hif-1 enhances the radio-resistance of mouse MSCs. Front Physiol. 2018:9:439

115. Arbeit JM. Quiescent hypervascularity mediated by gain of HIF-1 a function. Cold Spring Harbor Symp Quant Biol. 2002;67:133-42.

116. Sang N, Stiehl DP, Bohensky J, Leshchinsky I, Srinivas V, Caro J. MAPK signaling up-regulates the activity of hypoxia-inducible factors by its effects on p300. J Biol Chem. 2003;278:14013-9.

117. Song G, Ouyang G, Bao S. The activation of Akt/PKB signaling pathway and cell survival. J Cell Mol Med. 2005;9:59-71. 
118. Zhang Z, Yao L, Yang J, Wang Z, Du G. PI3K/Akt and HIF-1 signaling pathway in hypoxia-ischemia. Mol Med Rep. 2018;18:3547-54.

119. Minet E, Arnould T, Michel G, Roland I, Mottet D, Raes M, et al. ERK activation upon hypoxia: involvement in HIF-1 activation. FEBS Lett. 2000;468:53-8.

120. Huang X, Liu G, Guo J, Su Z. The PI3K/AKT pathway in obesity and type 2 diabetes. Int J Biol Sci. 2018;14:1483.

121. Ozaki K, Awazu M, Tamiya M, Iwasaki Y, Harada A, Kugisaki S, et al. Targeting the ERK signaling pathway as a potential treatment for insulin resistance and type 2 diabetes. Am J Physiol Endocrinol Metab. 2016;310:E643-51.

122. Franke TF. PI3K/Akt: getting it right matters. Oncogene. 2008:27:6473-88.

123. Dhillon AS, Hagan S, Rath O, Kolch W. MAP kinase signalling pathways in cancer. Oncogene. 2007;26:3279-90.

124. Leontieva OV, Demidenko ZN, Blagosklonny MV. Rapamycin reverses insulin resistance (IR) in high-glucose medium without causing IR in normoglycemic medium. Cell Death Dis. 2014:5:e1214-e1214.

125. Collins KK. The diabetes-cancer link. Diabetes Spectr. 2014;27:276-80.

126. Rehman S, Obaid A, Naz A, Ali A, Kanwal S, Ahmad J. Model-based in silico analysis of the PI3K/Akt pathway: the elucidation of cross-talk between diabetes and breast cancer. PeerJ. 2018;6:e5917.

127. Ramteke P, Deb A, Shepal V, Bhat MK. Hyperglycemia associated metabolic and molecular alterations in cancer risk, progression, treatment, and mortality. Cancers. 2019;11:1402.

128. Martin SD, McGee SL. Metabolic reprogramming in type 2 diabetes and the development of breast cancer. J Endocrinol. 2018;237:R35-46.

129. Korytkowski M, McDonnell ME, Umpierrez GE, Zonszein J. Patient guide to managing hyperglycemia (high blood sugar) in the Hospital. J Clin Endocrinol Metab. 2012;97:27A-28A.

130. Jeandidier N, Boullu-Sanchis S. Hyperglycemia and acute illness. Annales d'endocrinologie. 2006;67:224-32.

131. Cafaro RP. Hypoxia: its causes and symptoms. J Am Dental Soc Anesthesiol. 1960;7:4.

132. Norouzirad R, González-Muniesa P, Ghasemi A. Hypoxia in Obesity and Diabetes: Potential Therapeutic Effects of Hyperoxia and Nitrate [Internet]. Oxidative Medicine and Cellular Longevity. 2017; cited 2019 Oct 2. https://www.hindawi.com/journals/omcl/2017/5350267/

133. Al Tameemi W, Dale TP, Al-Jumaily RMK, Forsyth NR. Hypoxia-modified cancer cell metabolism. Front Cell Dev Biol. 2019:7:4.

134. Gilkes DM, Semenza GL. Role of hypoxia-inducible factors in breast cancer metastasis. Future Oncol. 2013;9:1623-36.

135. Nyengaard JR, Ido Y, Kilo C, Williamson JR. Interactions between hyperglycemia and hypoxia: implications for diabetic retinopathy. Diabetes. 2004;53:2931-8.

136. Regazzetti C, Peraldi P, Grémeaux T, Najem-Lendom R, Ben-Sahra I, Cormont $M$, et al. Hypoxia decreases insulin signaling pathways in adipocytes. Diabetes. 2009;58:95-103.

137. Al Qahtani A, Holly J, Perks C. Hypoxia negates hyperglycaemia-induced chemo-resistance in breast cancer cells: the role of insulin-like growth factor binding protein 2. Oncotarget. 2017:8:74635-48.

138. Blagosklonny MV. TOR-centric view on insulin resistance and diabetic complications: perspective for endocrinologists and gerontologists. Cell Death Dis. 2013;4:e964-e964.

139. Copps KD, White MF. Regulation of insulin sensitivity by serine/threonine phosphorylation of insulin receptor substrate proteins IRS1 and IRS2. Diabetologia. 2012;55:2565-82.

140. Papa V, Pezzino V, Costantino A, Belfiore A, Giuffrida D, Frittitta L, et al. Elevated insulin receptor content in human breast cancer. J Clin Invest. 1990:86:1503-10.

141. Giovannucci E. Insulin, insulin-like growth factors and colon cancer: a review of the evidence. J Nutr. 2001;131:3109S-S3120.

142. Calle EE, Kaaks R. Overweight, obesity and cancer: epidemiological evidence and proposed mechanisms. Nat Rev Cancer. 2004;4:579-91.

143. Yu H, Pardoll D, Jove R. STATs in cancer inflammation and immunity: a leading role for STAT3. Nat Rev Cancer. 2009:9:798-809.

144. Triner D, Shah YM. Hypoxia-inducible factors: a central link between inflammation and cancer. J Clin Invest. 2016;126:3689-98.

145. Garofalo C, Surmacz E. Leptin and cancer. J Cell Physiol. 2006;207:12-22.

146. Kelesidis I, Kelesidis T, Mantzoros CS. Adiponectin and cancer: a systematic review. Br J Cancer. 2006:94:1221-5.
147. Gabryelska A, Karuga FF, Szmyd B, Białasiewicz P. HIF-1 a as a mediator of insulin resistance, T2DM, and its complications: potential links with obstructive sleep apnea. Front Physiol. 2020;11:1035.

148. García-Jiménez C, García-Martínez JM, Chocarro-Calvo A, De la Vieja A. A new link between diabetes and cancer: enhanced WNT/ $\beta$-catenin signaling by high glucose. J Mol Endocrinol. 2014;52:R51-66.

149. Fisher WE, Boros LG, Schirmer WJ. Reversal of enhanced pancreatic cancer growth in diabetes by insulin. Surgery. 1995;1 18:453-7 (discussion 457-458).

150. García-Jiménez C, Gutiérrez-Salmerón M, Chocarro-Calvo A, GarcíaMartinez JM, Castaño A, De la Vieja A. From obesity to diabetes and cancer: epidemiological links and role of therapies. Br J Cancer. 2016:114:716-22.

151. Leone A, Di Gennaro E, Bruzzese F, Avallone A, Budillon A. New perspective for an old antidiabetic drug: metformin as anticancer agent. Cancer Treat Res. 2014;159:355-76.

152. Vergès $B$, Walter $T$, Cariou B. Endocrine side effects of anti-cancer drugs: effects of anti-cancer targeted therapies on lipid and glucose metabolism. Eur J Endocrinol. 2014;170:R43-55.

153. Zare $H$. Effects of salvia officinalis extract on the breast cancer cell line. SciMedicine J. 2019;1:25-9.

154. Bento CF, Pereira P. Regulation of hypoxia-inducible factor 1 and the loss of the cellular response to hypoxia in diabetes. Diabetologia. 2011:54:1946-56.

155. Liu L, Marti GP, Wei X, Zhang X, Zhang H, Liu YV, et al. Age-dependent impairment of HIF-1alpha expression in diabetic mice: Correction with electroporation-facilitated gene therapy increases wound healing, angiogenesis, and circulating angiogenic cells. J Cell Physiol. 2008;217:319-27.

156. Marfella R, D’Amico M, Di Filippo C, Piegari E, Nappo F, Esposito K, et al. Myocardial infarction in diabetic rats: role of hyperglycaemia on infarct size and early expression of hypoxia-inducible factor 1 . Diabetologia. 2002:45:1172-81.

157. Catrina S-B, Okamoto K, Pereira T, Brismar K, Poellinger L. Hyperglycemia regulates hypoxia-inducible factor-1alpha protein stability and function. Diabetes. 2004:53:3226-32

158. García-Pastor C, Benito-Martínez S, Moreno-Manzano V, FernándezMartínez AB, Lucio-Cazaña FJ. Mechanism and consequences of the impaired Hif-1 a response to hypoxia in human proximal tubular HK-2 cells exposed to high glucose. Sci Rep. 2019;9:15868.

159. Kihira Y, Miyake M, Hirata M, Hoshina Y, Kato K, Shirakawa H, et al. Deletion of hypoxia-inducible factor-1a in adipocytes enhances glucagonlike peptide-1 secretion and reduces adipose tissue inflammation. PLoS ONE. 2014;9:e93856.

160. Jiang C, Qu A, Matsubara T, Chanturiya T, Jou W, Gavrilova O, et al. Disruption of hypoxia-inducible factor 1 in adipocytes improves insulin sensitivity and decreases adiposity in high-fat diet-fed mice. Diabetes. 2011;60:2484-95.

161. Stiehl DP, Jelkmann W, Wenger RH, Hellwig-Bürgel T. Normoxic induction of the hypoxia-inducible factor 1alpha by insulin and interleukin1 beta involves the phosphatidylinositol 3-kinase pathway. FEBS Lett. 2002;512:157-62

162. Peiró C, Lorenzo Ó, Carraro R, Sánchez-Ferrer CF. IL-1ß Inhibition in cardiovascular complications associated to diabetes mellitus. Front Pharmacol. 2017:8:363.

163. Görgens SW, Benninghoff T, Eckardt K, Springer C, Chadt A, Melior A, et al. Hypoxia in combination with muscle contraction improves insulin action and glucose metabolism in human skeletal muscle via the HIF-1a pathway. Diabetes. 2017;66:2800-7.

164. Jögi A, Ehinger A, Hartman L, Alkner S. Expression of HIF-1a is related to a poor prognosis and tamoxifen resistance in contralateral breast cancer. PLOS ONE. 2019:14:e0226150.

165. Whelan KA, Schwab LP, Karakashev SV, Franchetti L, Johannes GJ, Seagroves TN, et al. The oncogene HER2/neu (ERBB2) requires the hypoxia-inducible factor HIF-1 for mammary tumor growth and anoikis resistance. J Biol Chem. 2013;288:15865-77.

166. Tanaka T, Ikegami Y, Nakazawa H, Kuriyama N, Oki M, Hanai J-I, et al. Low-dose farnesyltransferase inhibitor suppresses HIF-1a and snail expression in triple-negative breast cancer MDA-MB-231 cells in Vitro. J Cell Physiol. 2017;232:192-201. 
167. Litzenburger BC, Creighton CJ, Tsimelzon A, Chan BT, Hilsenbeck SG, Wang T, et al. High IGF-IR activity in triple-negative breast cancer cell lines and tumorgrafts correlates with sensitivity to anti-IGF-IR therapy. Clin Cancer Res. 2011;17:2314-27.

168. Hartman ZC, Poage GM, den Hollander P, Tsimelzon A, Hill J, Panupinthu $\mathrm{N}$, et al. Growth of triple-negative breast cancer cells relies upon coordinate autocrine expression of the proinflammatory cytokines IL-6 and IL-8. Cancer Res. 2013;73:3470-80.

169. Han S, Huang T, Hou F, Yao L, Wang X, Wu X. The prognostic value of hypoxia-inducible factor-1a in advanced cancer survivors: a meta-analysis with trial sequential analysis. Ther Adv Med Oncol. 2019;11:1758835919875851.

170. Li J, Zhang H, Guo X, Cui S, Liu H. Expression of HIF-1a and correlation with angiogenesis in tissue of breast cancer complicated with diabetes. Zhonghua Yi Xue Za Zhi. 2015;95:252-5.

171. Wang L, Fan J, Yan C-Y, Ling R, Yun J. Activation of hypoxia-inducible factor-1 a by prolonged in vivo hyperinsulinemia treatment potentiates cancerous progression in estrogen receptor-positive breast cancer cells. Biochem Biophys Res Commun. 2017;491:545-51.

172. Bartella V, Cascio S, Fiorio E, Auriemma A, Russo A, Surmacz E. Insulindependent leptin expression in breast cancer cells. Cancer Res. 2008;68:4919-27.

173. Garofalo C, Koda M, Cascio S, Sulkowska M, Kanczuga-Koda L, Golaszewska J, et al. Increased expression of leptin and the leptin receptor as a marker of breast cancer progression: possible role of obesity-related stimuli. Clin Cancer Res. 2006;12:1447-53.

174. Werb Z, Lu P. The role of stroma in tumor development. Cancer J. 2015;21:250-3.

175. Schäffler A, Schölmerich J, Buechler C. Mechanisms of disease: adipokines and breast cancer - endocrine and paracrine mechanisms that connect adiposity and breast cancer. Nat Clin Pract Endocrinol Metab. 2007;3:345-54.

176. Sánchez-Jiménez F, Pérez-Pérez A, de la Cruz-Merino L, Sánchez-Margalet V. Obesity and breast cancer: role of leptin. Front Oncol. 2019;9:596.

177. Banks AS, Davis SM, Bates SH, Myers MG. Activation of downstream signals by the long form of the leptin receptor. J Biol Chem. 2000;275:14563-72.

178. Zahid H, Subbaramaiah K, lyengar NM, Zhou XK, Chen I-C, Bhardwaj $\mathrm{P}$, et al. Leptin regulation of the p53-HIF1a/PKM2-aromatase axis in breast adipose stromal cells - a novel mechanism for the obesity-breast cancer link. Int J Obes (Lond). 2018;42:711-20.

179. Lee YS, Kim J-W, Osborne O, Oh DY, Sasik R, Schenk S, et al. Increased adipocyte $\mathrm{O} 2$ consumption triggers HIF-1a, causing inflammation and insulin resistance in obesity. Cell. 2014;157:1339-52.

180. Shao S, Zhao L, An G, Zhang L, Jing X, Luo M, et al. Metformin suppresses HIF-1a expression in cancer-associated fibroblasts to prevent tumor-stromal cross talk in breast cancer. FASEB J. 2020;34:10860-70.

181. Durrani IA, Bhatti A, John P. Regulatory microRNAs in T2DM and breast cancer. Processes. 2021;9:819.

182. Krutilina R, Sun W, Sethuraman A, Brown M, Seagroves TN, Pfeffer LM, et al. MicroRNA-18a inhibits hypoxia-inducible factor 1 a activity and lung metastasis in basal breast cancers. Breast Cancer Res. 2014;16:R78.
183. Yeo E-J, Chun Y-S, Cho Y-S, Kim J, Lee J-C, Kim M-S, et al. YC-1: a potentia anticancer drug targeting hypoxia-inducible factor 1. J Natl Cancer Inst. 2003;95:516-25.

184. Ece H, Cigdem E, Yuksel K, Ahmet D, Hakan E, Oktay TM. Use of oral antidiabetic drugs (metformin and pioglitazone) in diabetic patients with breast cancer: how does it effect serum Hif-1 alpha and 8Ohdg levels? Asian Pac J Cancer Prev. 2012;13:5143-8.

185. Nathan DM, Buse JB, Davidson MB, Ferrannini E, Holman RR, Sherwin $R$, et al. Medical management of hyperglycemia in type 2 diabetes: a consensus algorithm for the initiation and adjustment of therapy: a consensus statement of the American Diabetes Association and the European Association for the Study of Diabetes. Diabetes Care. 2009;32:193-203.

186. Wang J, Li G, Wang Y, Tang S, Sun X, Feng X, et al. Suppression of tumor angiogenesis by metformin treatment via a mechanism linked to targeting of HER2/HIF-1 a/NEGF secretion axis. Oncotarget. 2015;6:44579.

187. Orecchioni S, Reggiani F, Talarico G, Mancuso P, Calleri A, Gregato G, et al. The biguanides metformin and phenformin inhibit angiogenesis, local and metastatic growth of breast cancer by targeting both neoplastic and microenvironment cells. Int J Cancer. 2015;136:E534-544.

188. Kim A, Ma JY. Rhaponticin decreases the metastatic and angiogenic abilities of cancer cells via suppression of the HIF-1 a pathway. Int J Oncol. 2018;53:1160-70.

189. Manzi L, Costantini L, Molinari R, Merendino N. Effect of dietary $\omega-3$ polyunsaturated fatty acid DHA on glycolytic enzymes and Warburg phenotypes in cancer. Biomed Res Int. 2015;2015:137097.

190. Siddiqui IA, Sanna V, Ahmad N, Sechi M, Mukhtar H. Resveratrol nanoformulation for cancer prevention and therapy. Ann NY Acad Sci. 2015:1348:20-31.

191. Parsa N. Environmental factors inducing human cancers. Iran J Public Health. 2012:41:1-9.

192. Shlomai G, Neel B, LeRoith D, Gallagher EJ. Type 2 diabetes mellitus and cancer: the role of pharmacotherapy. J Clin Oncol. 2016;34:4261-9.

193. Nagao A, Kobayashi M, Koyasu S, Chow CCT, Harada H. HIF-1-dependent reprogramming of glucose metabolic pathway of cancer cells and its therapeutic significance. Int J Mol Sci. 2019;20:238.

194. Srinivas US, Tan BWQ, Vellayappan BA, Jeyasekharan AD. ROS and the DNA damage response in cancer. Redox Biology. 2019;25:101084.

195. Imtiyaz HZ, Simon MC. Hypoxia-inducible factors as essential regulators of inflammation. Curr Top Microbiol Immunol. 2010;345:105-20.

196. Balamurugan K. HIF-1 at the crossroads of hypoxia, inflammation, and cancer. Int J Cancer. 2016;138:1058-66.

\section{Publisher's Note}

Springer Nature remains neutral with regard to jurisdictional claims in published maps and institutional affiliations.

Ready to submit your research? Choose BMC and benefit from:

- fast, convenient online submission

- thorough peer review by experienced researchers in your field

- rapid publication on acceptance

- support for research data, including large and complex data types

- gold Open Access which fosters wider collaboration and increased citations

- maximum visibility for your research: over $100 \mathrm{M}$ website views per year

At BMC, research is always in progress.

Learn more biomedcentral.com/submissions 